Universidad de Lima

Escuela de Posgrado

Maestría en Derecho Empresarial

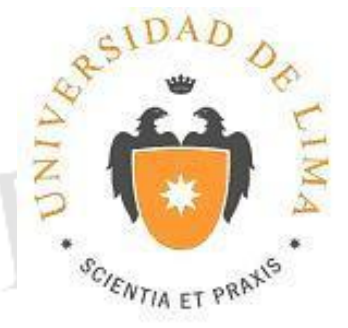

LA RESPONSABILIDAD DE LA SOCIEDAD BENEFICIARIA DE LA ESCISIÓN Y DE LA PARCIALMENTE ESCINDIDA FRENTE A LAS ACREENCIAS LABORALES: SALVAGUARDANDO LA

CONSTITUCIONALIDAD DEL ART. $389^{\circ} \mathrm{DE}$

\title{
LA LGS
}

Trabajo de investigación para optar el Grado Académico de Maestro en Derecho Empresarial

Joe Centeno Huaman y

Código 20132469
Sandro Almeyda López

Código 20132461

ASESOR: CARLOS CÁRDENAS ROBLES

$$
\text { Lima - Perú }
$$

Abril del 2017 


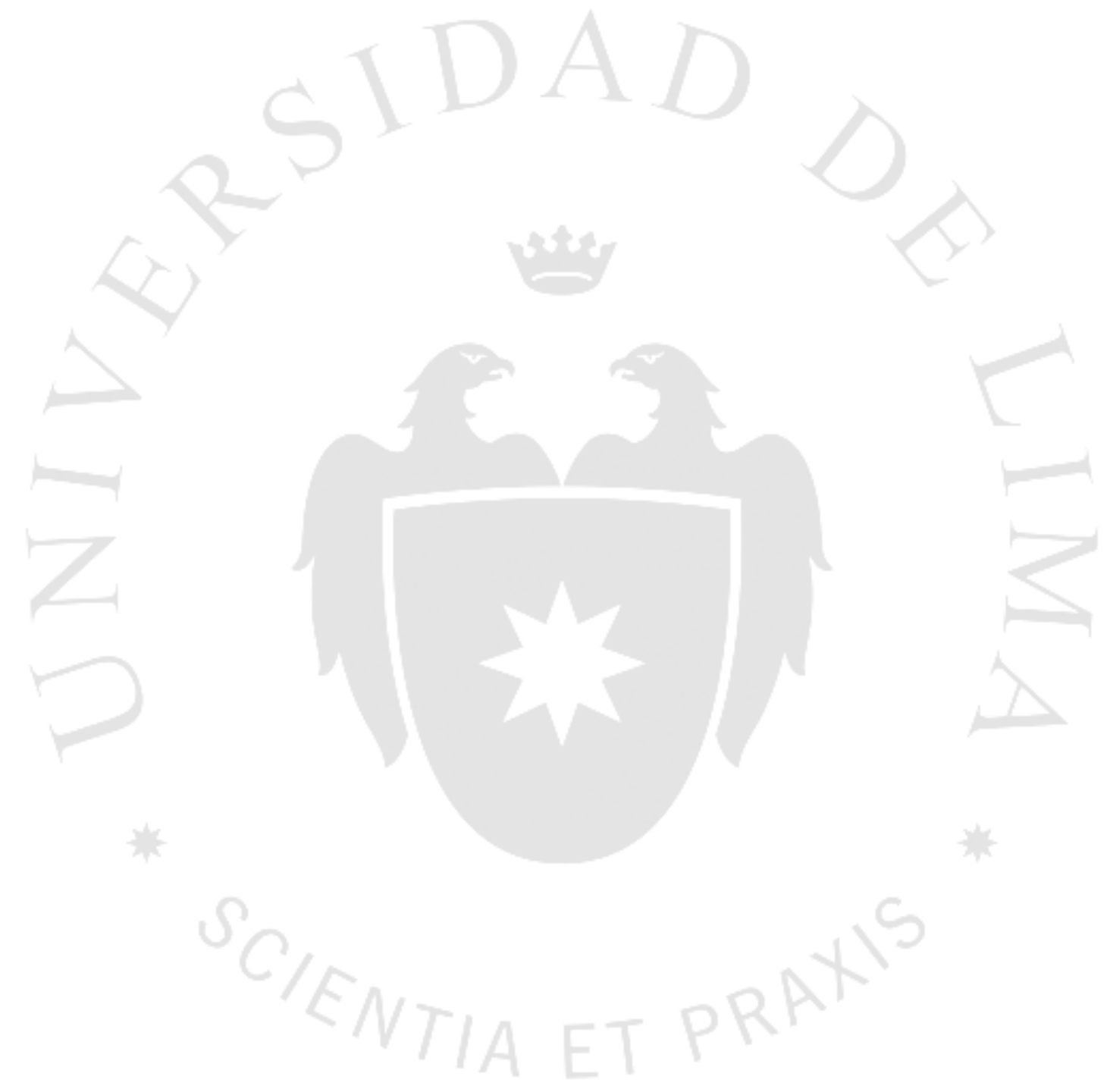




\section{LA RESPONSABILIDAD DE LA SOCIEDAD}

BENEFICIARIA DE LA ESCISIÓN Y DE LA PARCIALMENTE ESCINDIDA FRENTE A LAS ACREENCIAS LABORALES: SALVAGUARDANDO LA CONSTITUCIONALIDAD DEL ARTÍCULO $389^{\circ}$ DE LA LEY GENERAL DE SOCIEDADES 


\section{TABLA DE CONTENIDO}

INTRODUCCION 1

CAPITULO I: ASPECTOS PRELIMINARES: LA ESCISIÓN, FUNDAMENTOS, FINALIDAD Y CARACTERES DE LA RESPONSABILIDAD DE LAS SOCIEDADES INTERVINIENTES . .4

1.1.- La escisión empresarial.-................................................................4

1.1.1.- Fundamentos de la Escisión como distribución de capitales.- .................5

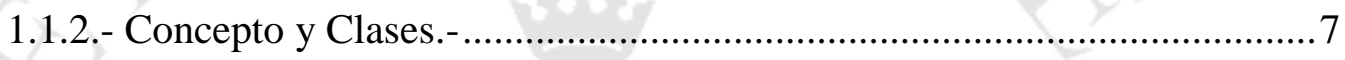

1.2.- Caracteres de la Responsabilidad de la Sociedad Escindida y la Beneficiaria en la LGS.10

1.3.- Finalidad de la escisión a la Luz del principio de la Buena Fe y respecto a la situación de abuso del derecho o fraude a la Ley..12

1.3.1.- La escisión empresarial y el principio de la buena fe . .12

1.3.2.- El Abuso del Derecho .13

1.3.3.- Actos realizados en fraude a la Ley .15

CAPITULO II: LAS ACREENCIAS LABORALES, CONCEPTUALIZACIÓN, PROTECCIÓN CONSTITUCIONAL Y CARÁCTER PERSECUTORIO DE LA DEUDA. .18

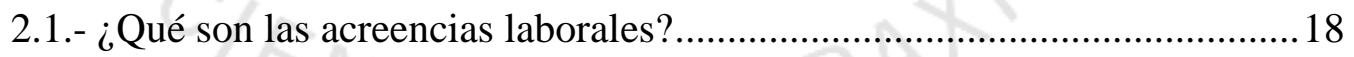

2.2.- Protección Constitucional . .20

2.2.1.- Prioridad en el Pago de las Remuneraciones y Beneficios sociales;

Fundamento del Art. $24^{\circ}$ de la Constitución. 20

2.2.2.- La Irrenunciabilidad de Derechos: Art. $26^{\circ}$ de la Constitución .... .21

2.3.- La Persecutoriedad de la deuda laboral a la luz del Decreto Legislativo $\mathrm{N}^{\circ}$ 856

2.3.1.- ¿Qué significa el carácter persecutorio de la deuda laboral? 
2.3.2.- Los supuestos contenidos en la Ley

2.3.3. ¿Todas las deudas son perseguibles?.... .25

CAPITULO III: LA RESPONSABILIDAD DE LA EMPRESA PARCIALMENTE ESCINDIDA Y LA BENEFICIARIA vS ACREENCIAS LABORALES: ¿QUE PREVALECE? .29

3.1.- Hacia un control difuso de la protección del crédito laboral. .29

3.2.- La Jurisprudencia como fuente del derecho .30

3.2.1. Evolución de los Criterios Jurisprudenciales sobre acreencias laborales 31

3.2.2. Actual posición de nuestros tribunales sobre el privilegio laboral, su carácter persecutorio frente a reorganización de sociedades (escisiones) que afecten a las primeras y su responsabilidad .38

3.3.- Impacto económico en las empresas intervinientes en el proceso de escisión: cuando la espada de Damocles cae.

3.4.-Nuestro Planteamiento para una aplicación coherente de la responsabilidad de la empresa parcialmente escindida y la beneficiaria frente al carácter persecutorio de la deuda laboral... 


\section{INTRODUCCION}

Hoy en día, el orden económico mundial requiere una manifestación clara del dinamismo empresarial que algunas figuras recogidas en nuestro ordenamiento así como otras importadas de otras latitudes le pueden dar, en aras del progreso de los estados, la consolidación de las economías nacionales y el bienestar de la comunidad, se ha multiplicado la tendencia de la reorganización de sociedades así como una concentración empresarial en ciertos casos, en algunos perdiendo la personalidad jurídica (La fusión por ejemplo) y aquella en la que no se pierda ésta (El cartel, el consorcio, etc.) siendo una de sus máximas expresiones la agrupación empresarial parafraseando a Uría (1994), se puede decir que los grupos de empresas son la respuesta a la organización económica cada vez más compleja. La formación de estos grupos obedece conforme nos dice el Echaíz Moreno (2001) a la interiorización de la filosofía empresarial "mejor unidos que desunidos", la misma que (continúa diciendo) va acompañada de la doble decisión de, por un lado, no sacrificar la autonomía jurídica de las empresas integrantes y de otro lado, estructurar mecanismos de control en el interior del grupo siendo este el tema central del asunto.

Ahora bien, conforme a lo expuesto podríamos decir que la forma predilecta de hacer empresa en la actual corriente expansionista es la que acabamos de mencionar pero ello no es del todo cierto, existe otra tendencia actual en nuestro medio que nos atrevemos a denominar una de total limpieza de capitales e inversiones el cual ha sido también válidamente reconocido por nuestra legislación y ampliamente aceptada por la doctrina, la misma que ha sido consagrada en diversas leyes como la francesa, portuguesa, española, mexicana e italiana y nos referimos concretamente a la escisión de sociedades la cual es una clara respuesta del derecho a los problemas de reestructuración y reorganización por cuanto una empresa que no se adecue al dinamismo del mercado tiende a fracasar en su objetivo más esencial; sin embargo, a pesar de tener un fundamento dogmático positivo previsto como herramienta que permita trasmitir a una empresa sus activos a través de un procedimiento simple tenemos que en nuestro País la utilización de esta figura ha sido en reiteradas ocasiones con intenciones oscuras de frustrar derechos de acreedores y en buena cuenta burlando 
obligaciones legales, conducta lamentablemente frecuente en nuestro medio, debido en una parte a que nuestra legislación nacional no ha dado una solución expresa.

En este escenario, tenemos que esta situación produce pues fundados temores en los acreedores sobre todos los titulares de acreencias laborales quienes normalmente no familiarizados con las normas societarias no hacen un uso debido de su derecho a oposición establecida en el artículo $383^{\circ}$ de la Ley General de Sociedades y que impide reclamo alguno generando un aparente clima de calma en la sociedad parcialmente escindida, y decimos aparente por cuanto si bien a primera vista parecería beneficioso para aquella empresa con vocación fraudulenta es en realidad una espada de Damocles que pende sobre la cabeza de la sociedad parcialmente escindida la cual conforme nos informa la jurisprudencia de nuestros tribunales trae consigo un desenlace negativo para el empresario y el dinamismo económico en sí por el elevado coste empresarial que esto significa así como el impacto económico que representa a la sociedad beneficiaria de la escisión más aún si tenemos en cuenta que nuestros tribunales vienen propugnando la constitucionalidad de la irrenunciabilidad de las acreencias laborales y ha venido estableciendo la responsabilidad de las sociedades beneficiarias en un claro intento de mantener la garantía unitaria que representaba el patrimonio de la escindida para sus acreedores tras el fraccionamiento y la distribución de aquél.

En ese sentido, consideramos que el problema que hemos advertido, a propósito de la responsabilidad de la sociedad escindida y la beneficiaria, es la falta de delimitación legal del carácter preferente del pago y de la persecutoriedad de los créditos laborales, ya que, como lo vamos a explicar los tribunales judiciales de nuestro país vienen utilizando dichos preceptos para desconocer lo regulado en el artículo $389^{\circ}$ de la Ley General de Sociedades, vulnerando con ello la seguridad jurídica que debe existir en toda sociedad.

Dicha falta de delimitación ha generado un problema relacionado, reiteramos, con los límites de responsabilidad de la empresa beneficiaria de la escisión, quien puede asumir los pasivos que se le transfieren, incluidos los de los trabajadores transferidos, conforme lo permite la Ley General de Sociedades, puesto que algunos jueces y tribunales, consideran que dicha empresa también debe asumir la responsabilidad de los pasivos (beneficios sociales) de los trabajadores que no fueron transferidos a ella, al amparo del principio de persecutoriedad de los créditos laborales y su carácter preferente de pago. 
Así las cosas entonces con la presente investigación intentaremos dar una solución a esta problemática que reconocemos se encuentra vigente en nuestro medio pero sin regulación y/o reconocimiento en toda nuestra frondosa legislación que ponga límites claros ante situaciones de abusos y/o intenciones evasivas así como fronteras claras en la responsabilidad de las sociedades beneficiarias de una escisión cuyos aportes más relevantes en la rama laboral provienen de elaboraciones doctrinarias y jurisprudenciales sobre los alcances de la misma, figura compleja que propicia una especie de quiebre entre la realidad material y lo jurídico siendo aquello lo que resulta necesario conciliar por cuanto ya sea de una aplicación ligera de esta figura de parte del empresario o porque negarlo del todo su utilización fraudulenta atenta directamente el espíritu de la norma contenida en el artículo $389^{\circ}$ de la Ley General de Sociedades el mismo que es necesario salvaguardad su constitucionalidad, por lo que urge su regulación legislativa.

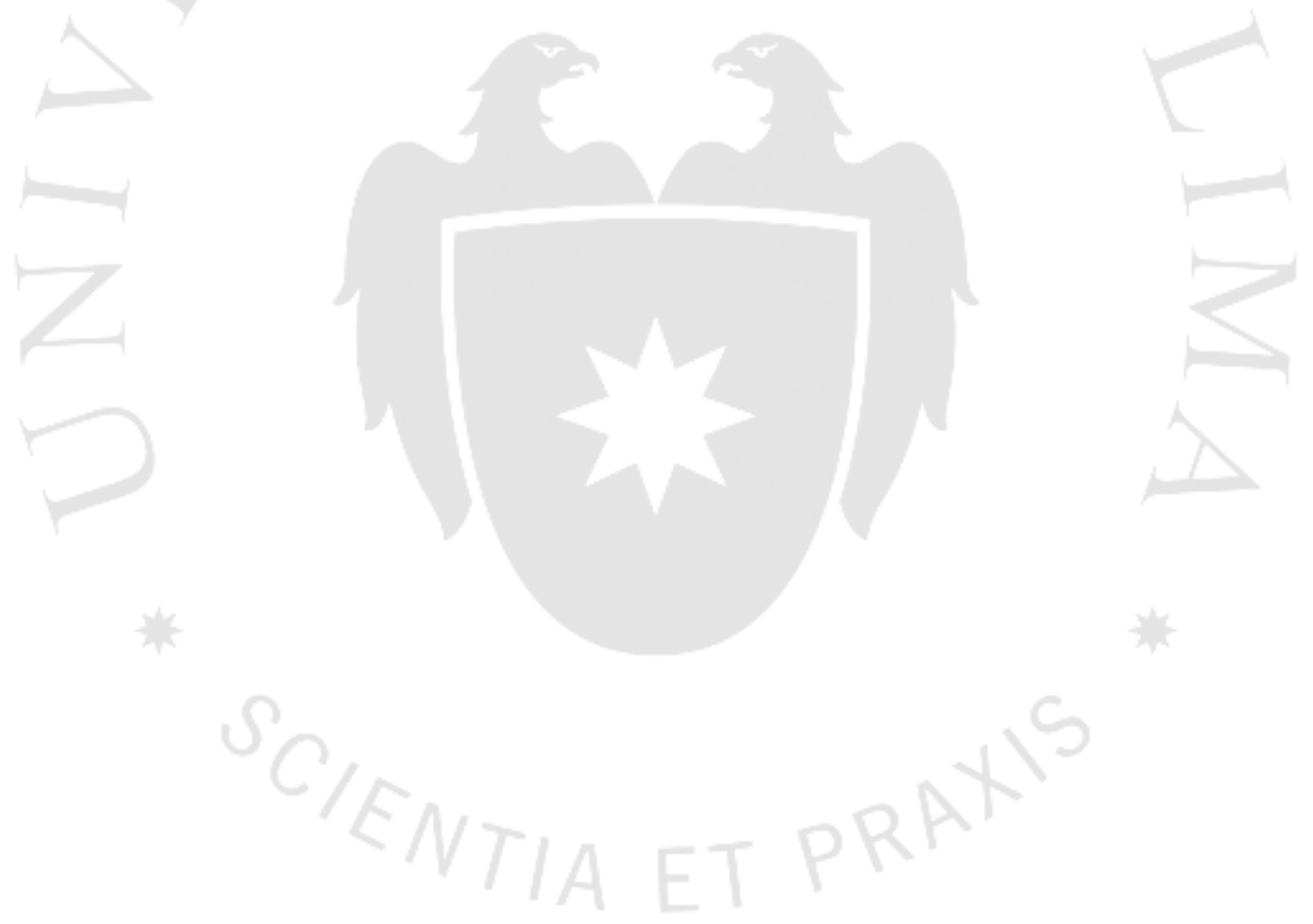




\section{CAPITULO I: ASPECTOS PRELIMINARES: LA ESCISIÓN, FUNDAMENTOS, FINALIDAD Y \\ CARACTERES DE LA RESPONSABILIDAD DE LAS SOCIEDADES INTERVINIENTES}

\section{1.- La escisión empresarial.-}

La escisión es la división de sociedades como alternativa de fragmentación o asignación de parte del patrimonio societario a la realización de una actividad mercantil través de otra entidad con autonomía económica y jurídica y constituye a diferencia de su primo antagónico la fusión en que éste último aglutina capitales, es decir unifica personas jurídicas y sus patrimonios, agrupando conforme nos dice Beaumont (Gallirgos - 2006): "a todos los socios en una sola sociedad fusionaría", mientras que en la escisión nos continúa diciendo: "implica un desdoblamiento de la persona jurídica con reparto de su patrimonio entre varias otras personas jurídicas" (pp. 123); y es así entonces que podemos afirmar que la escisión tiene como sinónimo a la "división de sociedades", de ahí que los efectos económicos que de ella se derivan son la desconcentración y especialización empresarial separando el grupo original societario, desconcentración que permite en muchos casos volver a tomar las riendas de una sociedad que ha alcanzado tal magnitud que hace inviable e inmanejable su administración.

Esta figura bastante estudiada y aceptada por la doctrina tiene pues fundamentos dogmáticos claros cimentados en una constante mutación del mercado que a su vez le dotan de características particulares conforme a sus alcances y finalidad y si bien el marco conceptual, características, modalidades y procedimiento recién nos fue presentado por la dación de la vigente LGS tenemos que su regulación es moderna y muy completa casi en todos sus aspectos (sobre todo reglamentarios y constitutivos) pero no así en lo referente a la responsabilidad de la empresa parcialmente escindida y la sociedad beneficiaria a quienes la norma le dedica un solo artículo, para ello es preciso realizar una rápida pero sustancial inmersión en la figura materia de estudio para poder entender la problemática que la misma puede y viene en realidad generando. 


\subsection{1.- Fundamentos de la Escisión como distribución de capitales.-}

El proceso de concentración de sociedades, se inicia en el siglo XIX y adquiere un auge notable en el siglo XX. Las grandes concentraciones empresariales se sucedieron unas a otras, generalmente por la vía de las fusiones y, paralelamente, por otros métodos indirectos que han sido denominados por la doctrina como "fusiones impropias", pues en ellas no se produce la consolidación de dos o más sociedades en una sola ni tampoco la transferencia de los patrimonios a una sociedad absorbente o incorporante, como en la fusión propia o legal. Sin embargo, en la misma medida en que las concentraciones y las fusiones aportaban una serie de resultados positivos para las empresas agrupadas, empezaron a aparecer determinados efectos perniciosos y nocivos como producto del crecimiento muchas veces desmedido, la organización empresarial agrupada tendió a perder ese dinamismo que al principio lo caracterizó y que tan buenos resultados le propicio en un inicio, decantándose al final con el decurso ingrato del tiempo, en ineficiencia de la empresa.

La administración de la gran empresa fusionada terminaba destinando cada vez más recursos a administrarse a ella misma, antes que dedicarlos a mejorar o a aumentar la producción, en algunas otras ocasiones se encontraban obligadas a desarrollar una serie de nuevas actividades (y que antes no tenía ni la necesidad y muchos menos el objetivo de realizar) pues la empresa que había devenido en gigante tendía a incursionar en negocios vinculados, paralelos o distintos a los de su actividad original. Es precisamente ante estos problemas producto de un aglutinamiento desmedido y/o no precipitado que surgen serios problemas al interior de un sistema administrativo que se desborda y que muchas veces no se vislumbraron al iniciarse un proceso de fusión o concentración, es por ello que surge la imperiosa necesidad de reorganizar la empresa o las empresas del grupo y reencontrarse con la dinámica y la eficiencia que antes demostraba

El pionero de esta figura y a quien debemos atribuirle su nacimiento positivo y evolución es a Francia e inmediatamente después a Italia y con bastante agrado posteriormente parte de su evolución a Argentina, aunque en el derecho alemán y español, entre otros, se presentaron casi simultáneamente, obedeciendo a fenómenos políticos y económicos semejantes. Según nos cuenta la historia, el procedimiento de escisión se presentó originalmente en el derecho positivo por conducto de la legislación tributaria tanto en Francia como en Italia y Argentina. 
Así en Francia, como una necesidad de racionalización de los elementos económicos, financieros y productivos de las empresas, los abogados de empresas solicitaron al legislador que los beneficios del régimen fiscal acordado para las fusiones se extendieran a la división de sociedades, lo que lograron a partir de 1948, mediante la expedición de la ley 16 de julio de ese año y aunque la escisión era controvertida en la doctrina, su empleo en la práctica motivó decisiones jurisprudenciales que la admitieron, así lo afirma Duque Domínguez (1987) "los procesos de escisión o división de sociedades surgidos en la práctica del derecho de la reestructuración de empresas en el derecho francés, se remontan a los años 1949 y 1952” (pp.58). Reafirmándose como pioneros posteriormente con la dación de la Ley general de Sociedades de 1966 quien por primera vez regula sustantivamente la escisión.

Así las cosas, tenemos que una de las razones fundamentales que motivo esta forma de reorganización es precisamente coadyuvar a una mejor racionalización de las actividades económicas de una empresa al permitirle dividir la totalidad o parte de su activo, pasivo o capital social y redistribuir el objeto social de la institución empresarial tenemos que se pone en evidencia la clara relación que existe entre la fusión y la escisión, por cuando ambas - siguiendo a Montoya Alberti (2004):

Son una respuesta del derecho a problemas de reestructuración y reorganización de empresas. La sociedad que no se adecua a las condiciones del mercado tiende a fracasar, es así que la respuesta del derecho a esta situación es brindar la herramienta que permita reorganizar la empresa mediante la transmisión de sus activos a través de un procedimiento simple. (pp. 112)

Buscando una solución clara a problemas de sobredimensionamiento de la empresa, el cual por un crecimiento exagerado o imprudente de las unidades o conjuntos empresariales pudiendo resolver la crisis de las empresas bajo esta modalidad, separando el patrimonio deficitario para su reactivación, o para solucionar problemas internos entre los socios; sin embargo, no solo los problemas son aliciente único de optar por esta medida, es bien reconocido a lo largo de los años que puede ser motivación de escindir una empresa por ejemplo la especialización de las distintas actividades que realiza una empresa para tomar una actividad inviable por su ejecución conjunta con otras completamente diferentes y hacerla rentable en forma separada, asimismo otra razón es también la descentralización de las actividades realizadas por la 
sociedad en varias áreas geográficas para poder obtener una mayor presencia en dichos puntos al contar cada una con una administración y sustentación propia.

Bajo estas perspectivas tenemos entonces que la escisión empresarial como figura resultaba más que necesaria para dotarle a las empresas de las condiciones suficientes y prácticas para encarar los drásticos cambios que experimento el enorme crecimiento económico acaecido el siglo pasado así como a una cultura de globalización fuertemente arraigada, así como para maximizar la eficiencia en las diversas actividades de las empresas, figura que fue importado recién por nuestra actual LGS y que sin mediar explicación alguna fuera ignorada por las anteriores legislaciones.

\subsection{2.- Concepto y Clases.-}

Es imposible tener una conceptualización clara de esta forma de reorganización societaria sin apoyarnos en las definiciones que autorizada doctrina internacional como nacional han realizado al respecto así tenemos entonces que Julio C. Otaegui (1981) define a la escisión en su obra «Fusión y Escisión de Sociedades Comerciales» de la siguiente manera:

(...) La escisión estriba fundamentalmente en el desdoblamiento de una persona jurídica con el reparto de su patrimonio en varias personas jurídicas, y en el caso de sociedades con la atribución de los socios de la sociedad escindente del carácter de socios de la sociedad escisionaria. (pp. 40)

Complementa estas definiciones el eminente profesor español Uría (1994) en su obra «Derecho Mercantil» nos decía lo siguiente:

(...) Se entiende por escisión: 1. La extinción de una sociedad anónima, con división de todo su patrimonio en dos o más partes, cada una de las cuales se traspasa en bloque a una sociedad de nueva creación o es absorbida por una sociedad ya existente. 2. La segregación de una o varias partes del patrimonio de una sociedad anónima sin extinguirse, traspasando en bloque lo segregado a una o varias sociedades de nueva creación o ya existentes. (pag. 129)

En esta línea en la obra «La escisión de sociedades en el derecho español», Guasch (1993) considera a la escisión como:

(...) la operación del Derecho de sociedades consistente en fragmentar total o parcialmente el patrimonio de una sociedad en una o más partes, transmitiendo en 
bloque cada fracción patrimonial escindida a una o varias sociedades existentes o de nueva creación, mediante la atribución a los socios de la sociedad escindida de acciones o participaciones procedentes de la sociedad o sociedades beneficiarias. (pp. 69)

En el ordenamiento jurídico español, fuente directa de nuestra legislación mercantil, la escisión venía regulada en principio y hasta la aprobación de la Ley 3/2009, de 3 de abril, sobre modificaciones estructurales de sociedades mercantiles, en el Real Decreto Legislativo 1564/1989, de 22 de diciembre, por el que se aprueba el Texto refundido de la Ley de Sociedades Anónimas (en adelante, TRLSA), en el Capítulo VIII sección $3^{\text {a }}$ art. 252-259 para el caso de sociedades anónimas. Así en esta última norma la escisión venia definida en el artículo precedente de la siguiente manera:

1. Se entiende por escisión:

a) La extinción de una sociedad anónima, con división de todo su patrimonio en dos o más partes, cada una de las cuales se traspasa en bloque a una sociedad de nueva creación o es absorbida por una sociedad ya existente.

b) La segregación de una o varias partes del patrimonio de una sociedad anónima sin extinguirse, traspasando en bloque lo segregado a una o varias sociedades de nueva creación o ya existentes.

2. Las acciones o participaciones sociales de las sociedades beneficiarias de la escisión deberán ser atribuidas en contraprestación a los accionistas de la sociedad que se escinde, los cuales recibirán un número de aquéllas proporcional a sus respectivas participaciones, reduciendo la sociedad, en su caso y simultáneamente, el capital social en la cuantía necesaria.

En los casos en que existan dos o más sociedades beneficiarias, la atribución a los accionistas de la sociedad que se escinde de acciones o participaciones de una sola de ellas requiere el consentimiento individual de los afectados.

3. Sólo podrá acordarse la escisión si las acciones de la sociedad que se escinde se encuentran íntegramente desembolsadas.

4. Las sociedades beneficiarias de la escisión pueden tener forma mercantil diferente a la de la sociedad que se escinde. 
Posteriormente con la aprobación de la Ley sobre modificaciones estructurales de las sociedades mercantiles (LME) del 03.04.2009 se produce un cambio drástico en algunos aspectos de la norma fundamentalmente en las obligaciones de publicidad agregando como novedad en relación a la anterior norma un nuevo tipo de escisión: "la segregación de la sociedad".

Ya en territorio nacional tenemos que el artículo 367 de la Ley General de Sociedades nos brinda el siguiente concepto de escisión: "por la escisión una sociedad fracciona su patrimonio en dos o más bloques para transferirlos íntegramente a otras sociedades o para conservar uno de ellos."

Siguiendo con la definición tenemos que mencionar que la mayoría de las doctrinas y las legislaciones que la incorporan a sus normas sustantivas efectúan una clasificación partiendo del elemento de la transmisión parcial o total de la sociedad que se escinde (nótese que dicha característica ya estaba presente en la definición española citada precedentemente) y en base a tal criterio podemos distinguir entre escisión parcial y escisión total, así nos lo hace notar Callirgos (2006) cuando nos decía que:

La escisión total implica la división de la totalidad del patrimonio de la sociedad escindente en dos o más partes, su atribución a dos o más sociedades existentes o nuevas y, finalmente, la entrega de las acciones de la sociedad receptora de cada parte del patrimonio a favor de los accionistas de la escindente; mientras que, la escisión parcial implica la transmisión de solamente una parte del patrimonio de la escindida sin que ello produzca la extinción de la misma. (Pag.103)

En la misma línea de razonamiento encontramos a Montoya Manfredi (2004) denominando a la primera la que se refiere el Dr. Beaumont como escisión pura y simple o propia y a la segunda como escisión impropia.

Nuestra Ley, ampara ambas clases de escisiones cuando señala que la escisión puede adoptar alguna de las siguientes formas conforme a su texto mismo, el Art. $367^{\circ}$ distingue la escisión propia o total (Inc. 1) que entraña necesariamente la extinción de la personalidad jurídica de la sociedad escindente por la división total del patrimonio de ésta transferida a favor de otras sociedades; así como la escisión impropia o parcial (Inc. 2) que lógicamente no entraña la extinción de la sociedad escindente y mantiene en su poder una de las porciones patrimoniales en que se fracciona la sociedad. 


\section{2.- Caracteres de la Responsabilidad de la Sociedad Escindida y la Beneficiaria en la Ley General de Sociedades.-}

Conforme al texto expreso de nuestra Ley General de Sociedades se establece a la letra en el artículo $389^{\circ}$ la responsabilidad de la sociedad escindida y aquella beneficiaria de la misma cuando nos dice:

Desde la fecha de entrada en vigencia de la escisión, las sociedades beneficiarias responden por las obligaciones que integran el pasivo del bloque patrimonial que se les ha traspasado a han absorbido por efectos de la escisión.

Las sociedades escindidas que no se extinguen, solo responden frente a las sociedades beneficiarias por el saneamiento de los bienes que integran el activo del bloque patrimonial transferido, pero no por las obligaciones que integran el pasivo de dicho bloque.

Estos casos admiten pacto en contrario.

Texto que resulta sumamente claro y que es evidente ha optado siguiendo a Beaumont (2006): "por uno de los caminos más modernos del derecho societario, en materia de escisión”(Pp. 822) de realizar una especie de corte y diferenciación de la responsabilidad de las sociedades intervinientes, tomando como referencia la fecha de entrada en vigencia de la escisión, pudiéndose advertir que desde que ésta se produce la sociedad beneficiaria SOLO responderá por las obligaciones que integren el pasivo del bloque patrimonial que se les ha traspasado o han absorbido por efectos de la misma, en consecuencia solo serían ( $y$ exclusivamente) estas las obligaciones a las cuales estaría compelida la empresa beneficiaria de la escisión a honrar en caso de que al momento de transferirle un bloque patrimonial exista como parte adherida al mismo un pasivo impago.

Por otro lado, de igual forma se entiende claramente del artículo citado que las sociedades escindidas (obviamente nos referimos a aquellas en los que por la escisión no se hubiera extinto la escindente, es decir a una escisión por segregación) solo responden frente a las sociedades que reciben el patrimonio escindido por el saneamiento de los bienes que integran el patrimonio traspasado, pero no por las obligaciones que integran el pasivo de dicho bloque dado que tal y como ya mencionamos en el párrafo anterior después de la entrada en vigencia de la escisión y 
conforme al artículo en comento es la sociedad beneficiaria quien responde por dicho pasivo, eximiéndose si podemos utilizar el término la sociedad escindida de responder por dichas obligaciones por haber sido trasladadas a otra nueva ( $o$ no $)$ empresa.

Conforme a lo expuesto se evidencia la posición de nuestra normativa que diferencia en forma concluyente la responsabilidad de los partícipes de una escisión el que sin mayores complicaciones direcciona en forma puntual sobre a quién en todo caso deberían dirigirse los acreedores para exigir el cumplimiento de sus obligaciones, de esta forma nuestra normativa se aleja de su referente español el cual en su artículo $259^{\circ}$ de la Ley General de Sociedades establece:

En defecto de cumplimiento por una sociedad beneficiaria de una obligación asumida por ella en virtud de la escisión, responderán solidariamente del cumplimiento de la misma, las restantes sociedades beneficiarias hasta el importe del activo neto atribuido en la escisión a cada una de ellas y, si la sociedad escindida no ha dejado de existir como consecuencia de la escisión, la propia sociedad por la totalidad de la escisión.

Si bien conforme nos comenta Beaumont (2006) en un primer momento en la construcción de nuestra actual normativa se opinó que: "debería contemplarse la solidaridad de la empresa escindida y las beneficiarias, sea que se trate de división o segregación, pues el activo fijo que sirve de garantía para que el acreedor cobre sus créditos termina diseminado como parte del patrimonio de otras empresas" (Pp.132) 1 , tenemos que ante dicha postura (claramente importado del derecho europeo, específicamente, del español) se hicieron 3 objeciones:

- Que más práctico resultaba el derecho de oposición.

- Que la regla de solidaridad podría resultar injusta dado que se podría terminar exigiendo a una empresa que ha recibido poco activo de la escindente el pago de obligaciones que la beneficiaria, en puridad, no ha incumplido.

- Que es impracticable cuando la sociedad se escinde en muchas sociedades que tienen una pequeña parte del activo cada una.

\footnotetext{
${ }^{1}$ (CALLIRGOS, 2006)
} 
Postura que termino cediendo ante las objeciones descritas y que se reflejan de la construcción del artículo $383^{\circ}$ de la Ley General de Sociedades (Referente al derecho de Oposición) el cual debemos interpretarlo en forma copulativa con el artículo $384^{\circ}$ del mismo cuerpo normativo (que regula lo referente a la sanción para la oposición de mala fe o sin fundamento) objeciones con las cuales estamos completamente en discordia por cuanto si bien los artículos referidos dan la posibilidad al acreedor de poder oponerse tenemos que el mismo no resulta del todo coherente con lo regulado en el posterior artículo $389^{\circ}$ de la mencionada ley, el cual fundado en el "modernismo" de la actividad empresarial vacía de contenido el espíritu de la escisión.

\section{3.- Finalidad de la escisión a la Luz del principio de la Buena Fe y respecto a la situación de abuso del derecho o fraude a la Ley.-}

\subsection{1.- La escisión empresarial y el principio de la buena fe}

Es imposible abordar o tratar de enunciar una finalidad válida de esta forma de reorganización societaria sin tener en cuenta lo que informa el principio enunciado dentro de todo nuestro sistema legal y sobre todo a la especial parte referente a los negocios jurídicos, en dicho sentido se debe comenzar entendiendo la vitalidad e importancia de los principios generales del derecho como norma enunciativa de valor genérico que coadyuvan y decantan en una mejor comprensión de todo el ordenamiento jurídico.

En esta línea podemos afirmar entonces, siguiendo a Silva Vallejo (1985) que los principios generales del derecho pueden definirse como "los postulados axiomáticos, los fundamentos basilares, los puntos de partida en los que se inspira y sobre los que reposa la ciencia del Derecho Civil y de Proceso ”(pp. 487), los cuales no podemos limitar a una razón de ser meramente funcional sino que también debemos reconocer que aquellos están presentes en la creación del Derecho mismo, siendo uno de estos principios fundamentales el bastante conocido (aunque muchas veces solo como argumento superfluo) principio de la buena fe el cual podemos definir (sin ser nuestra intención conceptualizar este principio, pero consideramos necesaria una aproximación para entender lo que se quiere explicar) viene a ser una condición o estado del intelecto que se presenta como una guía de la voluntad o un modo de ser del juicio 
(ignorancia o error) y que determina la realización de una determinada conducta jurídicamente relevante dirigida a fines prácticos inmediatos, la cual tiene dos manifestaciones a saber: Buena fe subjetiva y objetiva y si bien la doctrina las ha tratado de encasillar dentro de un mismo concepto a ambas nociones debemos hacer una gran salvedad, si bien la aproximación a la idea dada líneas arriba corresponde a la buena fe subjetiva esta debe de ser complementada con la regla estructural de la buena fe objetiva el cual viene a ser una regla de conducta, una exigencia, un deber de obrar con corrección y lealtad en relación con otros, con quienes se pretende vincular.

Así las cosas, podemos afirmar entonces que la finalidad de la escisión empresarial no puede estar divorciada al principio que nos informa, por cuanto esta modalidad ha sido creada principalmente con una razón de ser y con un sentido real y sobre todo con una justificación que se advierta en los hechos y/o necesidades de la empresa devenida en demasiado grande y por ello inmanejable o por lo menos no económicamente rentable (por ejemplo transferir a nuevos accionistas la empresa escindida, utilizar el bloque escindido para otros fines comerciales, obtener el financiamiento de operaciones, eliminar costos administrativos que antes no existían, lograr un mejor grado de especialización en unidades más pequeñas, entre muchas otras justificaciones económicas y/o corporativas).

Por el contrario, de no existir esta razón de ser de la reorganización societaria o justificación objetiva sino un alejamiento de aquel deber de obrar con corrección y lealtad podríamos estar frente a un claro ejercicio abusivo del derecho y/o un acto fraudulento, dependiendo la vocación empresarial, conceptos que resultan prudente definir en la líneas siguientes para conocer a ciencia cierta que situaciones la constituyen.

\subsection{2.- El Abuso del Derecho}

Respecto a la situación o figura del "abuso del derecho" tenemos que no es una institución nueva sino que sus orígenes se remontan hasta el Derecho Romano, en el caso peruano, el Art. II del T.P. del Código Civil consagra esta figura al disponer que la Ley no ampara el abuso del derecho; así, ya hace muchos años el recordado profesor e innegable doctrina autorizada en el país Barandiarán (1984) señalaba que: 
se incurre en abuso del derecho cuando, en el ejercicio de tal derecho, el titular se excede manifiestamente de los límites de la buena fe de modo que dicho ejercicio no se compatibiliza con la finalidad institucional y la función social en razón de las cuales se ha reconocido el respectivo derecho (pp.25)

Ello ocasiona un desamparo de parte del sistema jurídico en general y también a las “normas generales de convivencia social” y por ende una situación de injusticia, siendo "la Doctrina nacional precisamente - conforme nos indica Espinoza Espinoza (2003) quien se ha preocupado por delimitar la noción del abuso del derecho y por proporcionar los siguientes elementos de juicio:

a) Tiene como punto de partida una situación jurídica subjetiva;

b) Se transgrede un deber jurídico genérico (buena fe, buenas costumbres, inspiradas en el valor solidaridad);

c) Es un acto ilícito sui generis,

d) Se agravian intereses patrimoniales ajenos y no tutelados por una norma jurídica especifica;

e) No es necesario que se verifique el daño; y

f) Su tratamiento no debe corresponder a la responsabilidad civil sino a la teoría general del derecho (pp.59)

Asimismo, es necesario mencionar que dentro de la teoría General del Abuso del Derecho, la doctrina ha desarrollado una importantísima sub-especie de la misma para lo que constituye el tema neurálgico de la presente investigación denominada "abuso de la personalidad jurídica" el cual consideramos de natural trascendencia por cuanto si bien nuestra Constitución Política consagra entre los derechos de la persona el poder asociarse con fines lícitos no es menos cierto que existen variados casos en los cuales el ejercicio de este derecho se produce de manera irregular, con el fin de evadir el cumplimiento de obligaciones o cometer fraude, desviándose así de los fines para los cuales se consagra jurídicamente la personalidad jurídica. Un Gran defensor y exponente de esta sub-especie, Fernández Sessarego (2001) nos señalaba abordando este tema que:

el abuso de la personalidad jurídica es aquella situación o circunstancia en la cual una organización de personas utilizan las ventajas que otorga la 
formalidad que se obtiene con la inscripción de dicha organización en el registro para obtener beneficios en su provecho o en el de terceros al margen de los propios intereses de la persona jurídica. Es decir, son los seres humanos integrantes de la organización los que emplean dichas ventajas en su favor o para cometer un fraude a la Ley” (pp.57)

Desarrollando entonces la conceptualización dada por los ilustres juristas recogidos tenemos que es claro entonces que las sociedades reconocidas por la LGS constituyen en estricto personas jurídicas, las cuales no están ajenas a incurrir en un ejercicio abusivo de los derechos que le confiere la Ley, por las diversas y oscuras intenciones que puedan envolver a sus integrantes y por lo tanto de presentarse o evidenciarse un mal uso de algún derecho que el ordenamiento reconoce, la persona jurídica estaría conculcando directamente un deber jurídico genérico como es la buena fe $\stackrel{2}{=}$ y por consecuencia desamparando al acto o negocio jurídico pretendido por la persona jurídica, situación muchas veces predecesora al cometimiento de un fraude a la Ley lo cual analizaremos en el siguiente punto.

\subsection{3.- Actos realizados en fraude a la Ley}

Es conocido por todos que de acuerdo al principio de autonomía privada que inspira el derecho civil patrimonial (el cual también constituye continente legal para la LGS) las personas se encuentran facultadas para regular libremente sus propios intereses en el ámbito del ordenamiento jurídico, libertad que se expresa en el poder de crear, modificar, regular y extinguir relaciones jurídicas obligacionales (como la constitución de una empresa en si misma conforme al carácter contractual de las sociedades) ahora bien dicha autonomía no es irrestricta, encontrando su límite en aquel ámbito regulado por normas de obligatorio cumplimiento o de carácter prohibitivo o sancionador. El fundamento de tal limitación la constituye pues la existencia de un conglomerado de reglas generales de organización social o principios elementales que deben ser respetados por todos para la preservación del orden establecido; conforme a esto entonces, y coincidiendo con Oreste Roca (2013): “los particulares solo se encuentran habilitados para regular sus relaciones jurídicas dentro del ámbito de actuación que el

\footnotetext{
${ }^{2}$ Principio que constituye pieza medular dentro de esta institución y que en efecto han reconocido dentro de la conceptualización realizadas por estos ilustrados juristas en sus enunciaciones.
} 
ordenamiento jurídico reconoce" (pp.68) encontrándose por consecuencia obligados a observar aquellas normas imperativas vigentes; sin embargo, nos continua diciendo

existe la posibilidad de que los destinatarios de tales normas pretendan, a través de una utilización fraudulenta de los instrumentos que la Ley les otorga para la satisfacción de sus intereses privados, eludir el cumplimiento de las mismas bajo la apariencia de una actuación sujeta al marco legal. (pp. 68)

La figura plateada en el párrafo anterior ha sido denominada por la doctrina como "negocio jurídico en fraude a la Ley", figura que ha sido interesantemente explicada en la Resolución N 0329-2005-TDC-INDECOPI, publicada el 09.04.2005 la cual señalo en el punto III.2 lo siguiente:
Mediante la figura del negocio en fraude a la Ley, los sujetos celebran un determinado negocio (o acto) jurídico con el propósito de alcanzar un resultado práctico que no guarda correspondencia alguna con los efectos que normalmente se pretenden conseguir a través de la realización de tal negocio, sino con la finalidad de obtener un resultado prohibido por contravenir el orden público, las buenas costumbres o alguna norma imperativa en particular. El elemento que caracteriza dicha modalidad de fraude es la apariencia de respeto a la norma que ofrece el acto celebrado, pero que en realidad oculta la finalidad de eludir su cumplimiento.

En nuestro ordenamiento jurídico no hay una regulación del fraude a la Ley en general aunque conforme vamos a ver más adelante encontramos claras referencias al mismo en diversos dispositivos (Así tenemos el inciso f) del Art. $7^{\circ}$ del D.S. $N^{\circ}$ 001-96TR, Literal b) del Art. $3^{\circ}$ del D.Leg. $N^{\circ} 856$, entre otras) evocaciones que son solo figurativas, ya que ha sido la construcción doctrinal y muchas veces jurisprudencial la que ha tratado de definirla como lo hemos apreciado del párrafo anterior, por lo que consideramos que habiendo asumido nuestro ordenamiento jurídico como real la existencia de la figura comentada, urge una regulación con contenidos directrices para su aplicación en las normas que hemos señalado por ejemplo.

Conforme a lo expuesto entonces, tenemos que tal y como pasa con el abuso del derecho, si bien las definiciones de fraude a la Ley pareciesen estar orientadas solo a las personas naturales estamos convencidos de que las personas jurídicas (como ficción 
jurídica pero con trascendencia material) también pueden cometer fraude a la Ley y realizar negocios jurídicos en fraude a la Ley, prueba de ello es que la tan de moda doctrina del levantamiento del velo societario la considera conforme a su construcción doctrinal como un presupuesto a concurrir en caso de querer aplicar esta teoría a las empresas, presupuestos que sabemos son: i) situación de control; ii) situación de abuso de derecho o fraude a la Ley; iii) respeto del principio de subsidiariedad. Bajo este razonamiento entonces tenemos que discrepamos con una afirmación bastante ligera (que esperamos haya reevaluado su razonar) de que las empresas no pueden cometer fraude a la Ley, sino solo los particulares, falaz afirmación que contravienen claramente no solo con una unánime posición doctrinal sino también constituye una negativa señal en la tendencia de restablecer la vigencia del principio de la buena fe en los actos de las personas jurídicas que debe de ostentar cualquier acto o negocio más específicamente como deber genérico esencial de un estado de derecho.

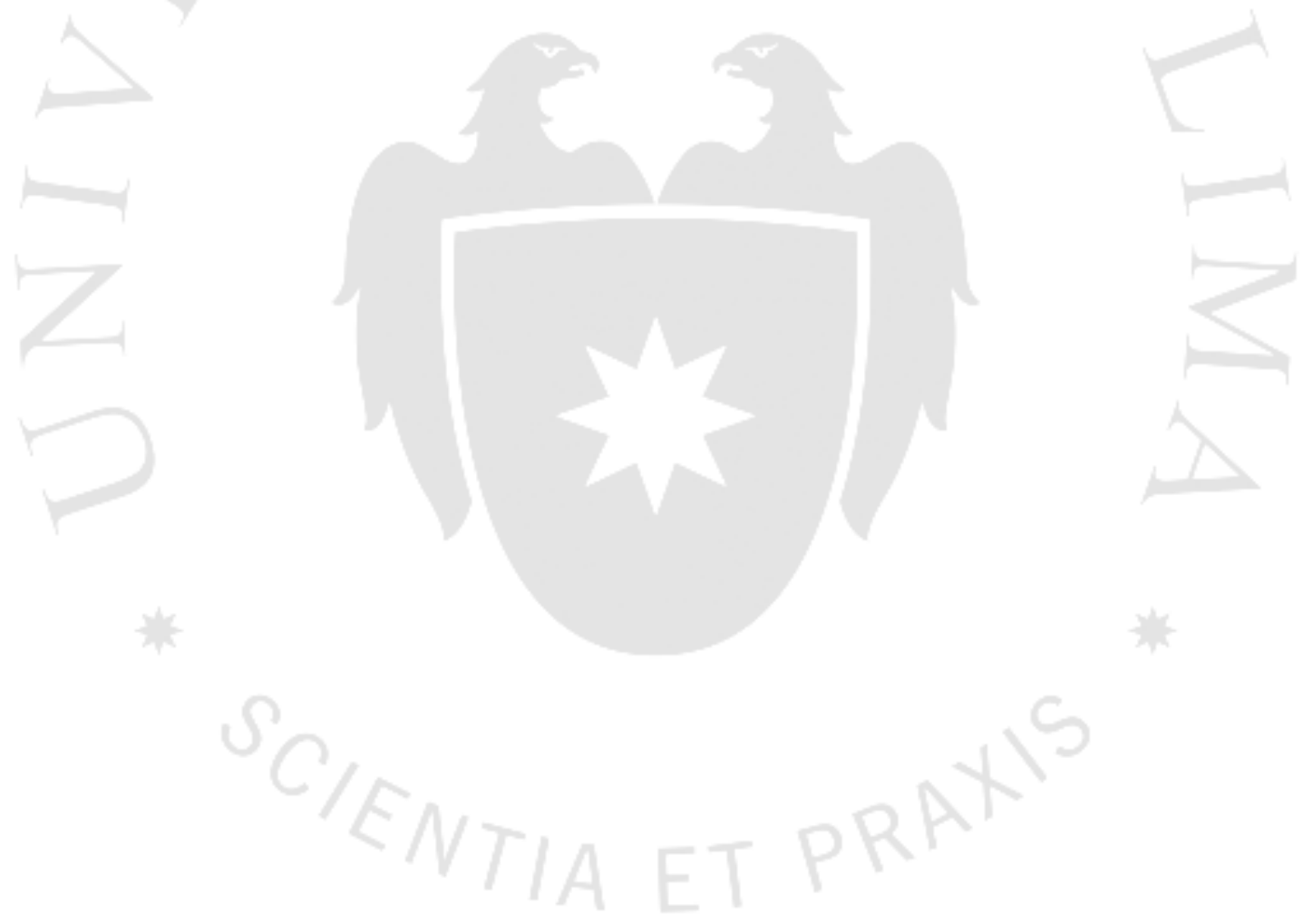




\section{CAPITULO II: LAS ACREENCIAS LABORALES, CONCEPTUALIZACIÓN, PROTECCIÓN CONSTITUCIONAL Y CARÁCTER PERSECUTORIO DE LA DEUDA.}

\section{1.- ¿Qué son las acreencias laborales?}

Si nos remontamos a la evolución histórica del concepto de acreencias laboral o también se denominado "crédito laboral", tenemos que el mismo siempre ha ido ligado a la evolución también del Derecho al trabajo que encuentra sustento en el interés general así como con el principio de solidaridad social el cual aparece recogido en las normas internacionales más importantes sobre derechos humanos $\underline{\mathbf{3}}$ que ha servido a su vez de sustento para el contenido actual que forma parte de nuestra actual Constitución, sin embargo, es prudente precisar (antes de tratar de definir este punto) que el carácter programático que coloca como responsabilidad al Estado de la promoción de condiciones para el progreso social y económico trasciende al campo estrictamente laboral, así las cosas conforme al artículo $23^{\circ}$ de la Constitución tenemos que se privilegia como política aquella dirigida a que los ciudadanos puedan acceder a un trabajo - en los términos planteados por el derecho al trabajo contenido en el artículo $22^{\circ}$ de la Constitución - y a que este sea productivo y cuando nos referimos a "trabajo productivo" tenemos que entender a aquel empleo que persigue un fin económico, una compensación por la actividad desarrollada. Al respecto siguiendo a Neves Mujica (1997): "el trabajo es productivo cuando se encamina a reportar un beneficio económico, de cualquier magnitud, a la persona que lo realiza” (pp.22). En el mismo sentido encontramos a Rubio Correo (1999) cuando nos dice que: "el empleo productivo es aquel que genera nueva riqueza" (pp. 212).

Conforme a lo expuesto, tenemos que la Constitución reconoce el derecho irrestricto a la contraprestación por el trabajo prestado, el mismo que está reconocido en el artículo $24^{\circ}$, derecho que al igual que el trabajo está reconocido en las más relevantes

\footnotetext{
${ }^{3}$ Entre estos tenemos a la Declaración Universal de Derechos Humanos; Pacto Internacional de Derechos Económicos, Sociales y Culturales; El protocolo adicional a la Convención Americana sobre Derechos Humanos.
} 
normas internacionales y que lo reconoce a la remuneración no solo como un elemento esencial del contrato de trabajo sino que constituye un derecho fundamental; sin embargo, de otro lado, el mismo articulado reconoce en su segundo párrafo que "el pago de las remuneraciones y beneficios sociales tienen prioridad sobre cualquier otra obligación del empleador", cuyo enunciación coloca sus cimientos en el carácter protector del derecho laboral, de tal manera que el crédito laboral tiene preferencia sobre cualquier otra; en este punto, y haciendo un paréntesis tenemos que decir que existe en un sector de la doctrina una posición que distingue la remuneración de los beneficios sociales, la cual consideramos es prudente y hasta necesaria determinar su real naturaleza de cada "concepto" para poder después con mayor criterio salvaguardar la legalidad de la definición del concepto de crédito laboral establecido en nuestro país.

Consideramos siguiendo a Toyama Miyagusuku (2005) que la remuneración es "todo lo que percibe el trabajador por los servicios prestados sea en dinero o en especie” (pp.534) el cual comprende según Lopez Basantía (1997) “aquellos conceptos que representan una ventaja o beneficio patrimonial" (pp.447) para el trabajador y su familia, definición que va en concordancia con el Art. $6^{\circ}$ de la LCPL el cual nos da una definición concreta sobre la remuneración, con exclusión obviamente de aquellos conceptos que se encuentren excluidos legalmente o que, por definición, no ingrese dentro de esta institución. A partir de lo expuesto podemos afirmar que la LPCL y su reglamento nos da una definición genérica, abierta y amplia sobre los alcances del concepto remunerativo y que se aprecia en la mayoría de legislaciones en América Latina.

Por otro lado los beneficios sociales han encontrado diferentes posiciones que intentaron delinearla o definirla algunas con mayor fortuna que otras, así tenemos que se

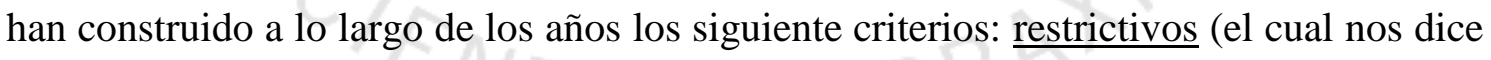
que solo los concepto reconocidos en la Ley de Consolidación de Beneficios Sociales constituye ello); criterio diferenciado (el que nos expone que la remuneración es diferente a los beneficios sociales) criterio legal (en esta posición se indica que los beneficios sociales son aquellos cuyo origen es legal o heterónomo); $\stackrel{4}{-} \sin$ embargo, y adscribiéndonos a la perspectiva de Toyama Miyagusuku (2005), consideramos que los beneficios sociales son:

\footnotetext{
${ }^{4}$ Se discrepa totalmente de esta postura por cuanto sabemos que existen beneficios sociales que provienen de la costumbre, convenio colectivo, contrato individual.
} 
Todos aquellos conceptos que percibe el trabajador por o con ocasión del trabajo dependiente. No importando su origen (legal, heterónomo, convencional o autónomo); el monto o la oportunidad de pago, la naturaleza remunerativa del beneficio, la obligatoriedad o la voluntariedad, etc. Lo relevante es que lo percibe el trabajador por su condición de tal. (pp.537)

Llegados a este punto entonces estamos en la posibilidad de establecer en rigor lo que podemos entender como crédito laboral, el mismo que ha sido definido en el Decreto Legislativo $N^{\circ} 856$ - siguiendo la interpretación más amplia definida en el párrafo anterior - y en coherencia con el artículo $24^{\circ}$ de la Constitución, por lo que, el crédito laboral es entendido como las remuneraciones, la CTS, las indemnizaciones y en general los beneficios establecidos por la Ley que se adecuen a los trabajadores. Además, son créditos laborales los aportes impagos más intereses y gastos a los sistemas de jubilación. Definición que conforme se evidencia engloba a todos los conceptos que con ocasión de la prestación de servicios perciba el trabajador con independencia de la fuente u origen, la cuantía, su duración, etc.

\section{2.- Protección Constitucional}

\subsection{1.- Prioridad en el Pago de las Remuneraciones y Beneficios sociales;} Fundamento del Art. $24^{\circ}$ de la Constitución.

Como consecuencia del carácter protector y tuitivo del Derecho al trabajo basado en la necesidad de "equilibrar" de alguna forma la desigualdad natural que existe entre el empleador y el trabajador, el Derecho laboral como doctrina ha establecido una serie de reglas a favor de la parte más débil en la relación laboral, sobre todo ante casos de insolvencia o incumplimiento de parte del empresario.

Una de estas instituciones, según Toyama Miyagusuku (2005) es precisamente el privilegio laboral, esto es:

El derecho de los trabajadores para cobrar en primer lugar sus beneficios sociales ante un concurso de acreedores del empleador, no resultando relevante que el crédito laboral sea anterior o posterior a uno de naturaleza civil o que se encuentre inscrito en los registros públicos, lo más importante es que nos 
encontremos ante un trabajador que tiene adeudos de carácter laboral. (pp. 187)

Inspirados en estos fundamentos doctrinarios tenemos que nuestra Constitución en la misma línea de las normas internacionales de Derechos Humanos, Convenio de la OIT $\underline{\mathbf{5}}$ reconoce el carácter alimentario de los beneficios sociales en donde la remuneración es el único o el principal ingreso para el trabajador y su familia, quien muchas veces (por no decir todas) desconoce de las operaciones comerciales de su empleador, por ello en respuesta a esas situaciones y sustentado en el principio protector del derecho laboral nuestra Constitución optó por proteger a la parte más débil de la relación laboral.

Así las cosas entonces es que se recoge en nuestra Carta Magna, en su Art. 24 segundo párrafo el principio del privilegio laboral como fundamento cuando nos indica que "el pago de las remuneraciones y beneficios sociales tienen prioridad sobre cualquier otra obligación del empleador" Así, el carácter prioritario de la remuneración y beneficios abarcaría los distintos mecanismos a través de los cuales se tutela su percepción efectiva por parte del trabajador $\mathrm{y}$, consecuentemente, garantizar la finalidad de la parte introductoria del mismo artículo esto es su finalidad: procurar para él y su familia el bienestar material y espiritual, como expresión indudable del principio protector del derecho del trabajo que ya mencionamos líneas arriba, es por ello que Samamé Morante (2007)

Dichos créditos tienen un orden superior de prelación sobre otro tipo de acreencias. Es por ello que tanto el constituyente como el legislador han establecido un conjunto de garantías dirigidas a asegurar la percepción, completa y puntual de las rentas saláriales. (pp. 313)

\subsection{2.- La Irrenunciabilidad de Derechos: Art. $26^{\circ}$ de la Constitución}

Uno de los paradigmas fundamentales del derecho al trabajo lo constituye sin lugar a dudas el principio harto conocido de irrenunciabilidad el mismo que se erige como el eje central de la protección que le da el Estado y todo el ordenamiento laboral en si al trabajador; así las cosas se entiende entonces que el principio de irrenunciabilidad de derechos es justamente el que prohíbe que los alcances de disposición del titular de un

\footnotetext{
${ }^{5}$ El Art. 11 de la OIT $N^{\circ} 95$ prescribe que los créditos laborales tienen preferencia en los casos de quiebra o liquidación de una empresa y deberán ser pagados antes que los acreedores ordinarios. Este convenio sabemos todos que si bien no ha sido ratificado por el Perú, tiene el carácter de recomendación.
} 
derecho recaigan sobre derechos originados en normas imperativas y sanciona - ergo con la invalidez la transgresión a dicha regla, fundamento que nos parece válido, como lo indica Ferro Delgado (2009)

Toda vez que carecería de eficacia que la legislación reconociera un conjunto de beneficios destinados a atenuar la condición de desigualdad entre el empleador y el trabajador, y simultáneamente se reconociese a éste la capacidad para renunciar o disponer de tales derechos. (pp.158)

Básicamente porque sería muy fácil para el empleador quien condicionando al trabajador dada su mejor posición en la negociación laboral imponga requisitos abusivos para por ejemplo el trabajador obtenga un empleo, reciba un aumento o mejore su estatus al interior de la empresa como por ejemplo privándose voluntariamente de derechos consagrados en la Ley o convenio colectivo, es por ello que Ferro Delgado (2009) señalo que "la conceptualización sobre la existencia de que ciertos derechos laborales deben necesariamente ser salvaguardados constituye la base de su indisponibilidad e irrenunciabilidad" (pp.158)

Así las cosas debemos precisar que un derecho puede nacer de una norma dispositiva o imperativa, en el primer caso el principio en comento no operará mientras que en el segundo caso el titular del derecho no puede abandonarlo por su voluntad lo que equivale a la renuncia, mientras que la disposición puede ser tolerada, la renuencia en base a este principio no.

Finalmente para cerrar la explicación de este principio tenemos que manifestar que, no todos los derechos laborales gozan de la prerrogativa de la irrenunciabilidad, como ya manifestamos líneas arriba habrá unos que admiten actos de disposición mientras que otros operarán con carácter de relativa imperatividad tal y como nos señala Neves Mujica(1997): "podrán ser imperativos hacia abajo y dispositivos hacia arriba, limitándose la imperatividad al aspecto indisponible de la norma, pero no así a la parte dispositiva" (PP.108). Dicho esto, debemos partir entonces del razonamiento que el principio de irrenunciabilidad opera únicamente frente a normas heterónomas (Leyo convenio colectivo) de carácter imperativo, dado que no es posible pactar derechos y beneficios por debajo de los regulados por el Estado a través de normas de origen privado. 
Entendido el principio de irrenunciabilidad revisemos la fórmula utilizada por nuestra Constitución Peruana, el cual conforme a su texto prevé que el carácter irrenunciable opera respecto de aquellos derechos expresamente reconocidos en la Constitución y la Ley, de lo que se podría entender que es posible entonces renunciar a derechos provenientes de otras fuentes, lo cual devela dos imprecisiones: por un lado ni todos los derechos nacidos en la Ley son irrenunciables y por el otro no solo los derechos que tienen como fuente la Ley son irrenunciables, sino también los que surgen de las demás normas imperativas como son los convenios colectivos. En esta misma línea interpretativa Blancas Bustamante (1994) señala que la irrenunciabilidad por pacto individual se extiende a los derechos que provienen del convenio colectivo (pp. 136) en el mismo sentido Neves Mujica (2012) proclama que "los convenios colectivos no pueden dejarse sin efecto por la autonomía individual como proclama el Art. $43^{\circ}$ de la LRCT que está implícito, además, en la fuerza vinculante de los convenios colectivos que enuncia la constitución"(pp. 136) a la luz de los razonamientos expuestos, a los cuales nos adscribimos coincidimos con el Profesor Neves en que hubiera sido conveniente una concordancia entre estos preceptos constitucionales al regular el principio que no en una sino en muchas ocasiones ha sido interpretada desafortunadamente por nuestros tribunales.

\section{3.- La Persecutoriedad de la deuda laboral a la luz del Decreto Legislativo $\mathrm{N}^{\circ} 856$}

\subsection{1.- ¿Qué significa el carácter persecutorio de la deuda laboral?}

Como sabemos el D. Leg. $\mathrm{N}^{\circ} 856$ fue promulgado el 25 de septiembre de 1996, con el objetivo de unificar la legislación correspondiente al tratamiento de la protección de los créditos laborales. Esta norma contiene, para tal efecto cuatro artículo aplicables como resulta evidente a las relaciones jurídicas existentes desde su promulgación; siendo su aspecto más importante el haber establecido precisamente el carácter persecutorio de los créditos laborales sobre los bienes del empleador.

Así las cosas tenemos que en lo referente al carácter persecutorio de los créditos laborales sobre los bienes del empleador debemos señalar que es un aspecto que cuya aceptación no ha sido pacífica el si está o no comprendido dentro del contenido esencial del Art. $24^{\circ}$ de la Constitución Política del Estado, o si es un derecho más bien de 
configuración legal. Derecho que también debemos recalcar ha sido desarrollado no por la Ley, sino que ha sido la Jurisprudencia y por ende nuestros tribunales quienes han marcado las pautas de su aplicación y alcances cimentándose claramente en el principio de despersonalización del empleador en el sentido de la Persecutoriedad que se restringe a los bienes transferidos por este a terceros.

Lo que nos quiere informar entonces conforme a lo expuesto el carácter persecutorio del crédito laboral, tenemos que constituye una respuesta clara del carácter protector del Derecho laboral, al privilegiar el crédito, sobre todo a aquel que es natural no siempre cuenta o está al tanto de las operaciones comerciales de su contratante y cimentado igualmente en dos principios: La irrenunciabilidad de derechos de los trabajadores y su abono con carácter prioritario.

\subsection{2.- Los supuestos contenidos en la Ley}

Como ya venimos manifestando existe una preferencia en los diversos sistemas jurídicos de contar con un ordenamiento que busque prevenir, fiscalizar o afrontar las eventuales maniobras de ciertos empleadores que suscriben una serie de contratos y operaciones para transferir sus bienes a terceros que podría ser su único sustento para el cobro de los adeudos de los trabajadores, disminuyendo irracionalmente el patrimonio del empleador que haga utópico la posibilidad de que estos últimos cobren sus acreencias.

Ahora bien, el Decreto legislativo $\mathrm{N}^{\circ} 856$, que ha sido el que ha recogido el mecanismo de protección en nuestro país, señala claramente la preferencia o prioridad que ejerce con carácter persecutorio de los bienes del negocio en los siguientes supuestos:

a) Cuando el empleador ha sido declarado insolvente y como consecuencia de ello, ha procedido con la disolución y liquidación de la empresa o su declaración judicial de quiebra.

b) En los casos de extinción de las relaciones laborales e incumplimiento de las obligaciones con los trabajadores por simulación y/o fraude a la Ley, es decir, cuando se compruebe que el empleador injustificadamente disminuye o distorsiona la producción para originar el cierre del centro de trabajo o 
transfiere activos a terceros o los aporta para la constitución de nuevas empresas, o cuando abandona el centro del trabajo.

c) La preferencia o prioridad también se ejerce cuando en un proceso judicial el empleador no ponga a disposición del Juzgado bien o bienes libres suficientes para responder por los créditos laborales adeudados materia de la demanda. $\underline{6}$

Este es entonces el diseño normativo de nuestro País para armonizar la legislación con el $2^{\circ}$ párrafo del Art. $24^{\circ}$ de la Constitución Política del Perú, en concordancia con las recomendaciones de los tratados internacionales ratificados por el País y en respuesta claro está de la tendencia doctrinal laboral internacional que propugna entre otras cosas la humanización del trabajo y la protección de sus recursos como fuente generadora de divisas para la clase dependiente.

\subsection{3. ¿Todas las deudas son perseguibles?}

Si bien tenemos que la redacción de los supuestos en que la "Persecutoriedad de los créditos laborales" se activa es clara, no es menos cierto que encendidos debates ha originado en la doctrina nacional, lo que aunado a originales interpretaciones de nuestros tribunales ha propiciado que en algunos casos se amplíe y en otros se restringa los alcances de los casos contenidos en la Ley.

Así las cosas tenemos que se han encontrado una posición que siguiendo a Cortez considera que esta opción constitucional debe de ser complementada por nuestra legislación y, a falta de ella, por la función jurisdiccional, e inclusive, como ha sucedido en el Perú, por la actuación administrativa (principalmente la de INDECOPI) $\underline{7}$ ahora bien precisamente a que este derecho no ha tenido un desarrollo legislativo copioso sino que ha sido la jurisprudencia la que desde antaño ha ido construyendo las pautas de su alcance es que en algunas ocasiones se han generado más zonas grises que aclaratorias basándose en principios de aplicación no pacífica en todos los casos.

Así tenemos por ejemplo la persecutoriedad relacionada con el principio de solidaridad el cual mezcla la naturaleza persecutoria de los créditos laborales por la

\footnotetext{
${ }^{6}$ Artículo 3 y 4 del D. Legislativo No 856

7 CORTEZ CARCELEN, Juan. "Los créditos laborales. Algunos temas de discusión” en, Análisis Laboral - Vol. XXVI N 301 - Julio - 2002. P. 65.
} 
existencia de la vinculación económica, si una de ellas es por ejemplo propietaria de las acciones y del inmueble en el que desarrolla sus actividades la segunda, de igual manera ha sido arduo el debate en la relación de la Persecutoriedad en relación con el principio de la temporalidad de vertiente civil y con mucho arraigo en materia registral (la cual propugna la preferencia del primero en el tiempo en inscribir algún derecho) e incluso con el principio de impenetrabilidad de también arraigo registral que nos informa (en una interpretación concordada con el Art. $656^{\circ}$ del C.P.C) que no puede inscribirse un título incompatible con otro ya inscrito. Aunque sea de fecha anterior $\mathbf{8}$

De lo expuesto entonces tenemos que la construcción jurisprudencial como fuente del derecho ha generado en múltiples casos contradictorias soluciones o aplicaciones de los supuestos contenidos en el Decreto Legislativo 856 estudiado, posiciones antes las cuales surge inevitablemente una interrogante: ¿Todas las deudas son perseguibles? Y de ser negativa la respuesta ¿Cuál es el límite?.

Hemos visto que los supuestos contenidos en el D. Leg. 856 es una enumeración taxativa que no contiene otras causales para activar esta preferencia, herramienta que conforme al espíritu de dicha Ley es excepcional; sin embargo, también hemos visto a lo largo de los años que existen pronunciamientos en donde realizando un control difuso de la constitucionalidad de las normas, declaro inconstitucional las limitaciones del D. Leg. 856, así entonces tenemos que para un sector de nuestros tribunales ( $y$ dependiendo también del factor tiempo el cual en muchas ocasiones se han llevado criterios) el carácter persecutorio debe tener una fórmula abierta y no taxativa, y si bien dicha posición resultaría interesante de cara a la defensa de los derechos laborales, propicia el debate sobre los alcances del derecho persecutorio.

Siguiendo autorizada doctrina nacional, creemos que el criterio (voluble en algunos casos) de que el derecho persecutorio no se limita a los supuestos descritos en el D. Leg. 856 puede resultar a veces lesivo y en otras injustificadas teniendo como consecuencia un fundado temor en los inversionistas que atentaría en forma directa contra otro principio constitucional que es precisamente la seguridad jurídica en las inversiones.

Así retomando lo que nos dice nuestro recordado Toyama Miyagusuku (2005) existen supuestos como:

\footnotetext{
${ }^{8}$ Principio recogido en el Art. $2017^{\circ}$ del Código Civil también conocido en la doctrina nacional como prioridad excluyente
} 
La transferencia de bienes en un proceso de privatización, la venta de un inmueble a un tercero varios años atrás a una insolvencia del empleador, transferencia de patrimonio sin que se aprecie una intencionalidad de fraude o evasión ni nos encontremos ante un caso de término de la relación laboral, etc.

Serían casos que deberían ser analizados con cautela. (pp. 191)

Sin embargo constituye un límite claro el hecho de que esta institución (Persecutoriedad) no debe de aplicarse respecto de las personas que integran una empresa, es decir, la Persecutoriedad se predica respecto de los bienes del empleador y no sobre los accionistas de la persona jurídica, no pudiendo hacer responsable entonces o repercutir una deuda sobre el patrimonio del accionista.

Si bien esta limitación ha sido de escasa atención en los tribunales y porque negarlo también de poco debate en la doctrina nacional, creemos que es posible suplir esta deficiencia con un criterio importado desde el derecho civil el "factor de atribución" y que si bien no es materia de análisis en el presente estudio podríamos apoyarnos en todos aquellos justificativos teóricos del porqué del traspaso del peso económico de uno a otro ente, es decir porque la segunda debe verse afectada; estos factores deben podernos permitir apreciar las manifestaciones o rasgos sintomáticos propios de una evasión laboral o permitirnos conocer y/o constatar una situación de riesgo de incumplimiento laboral como por ejemplo: incumplimiento reiterado del empleador en el pago de los beneficios sociales, la existencia de un desprendimiento injustificado del patrimonio de la empresa, la ausencia quizás de bienes adicionales del empleador que permitan garantizar el honramiento de sus deudas laborales, un cierre total o parcial de las operaciones de la empresa, la existencia de una elevada carga procesal o demandas en su contra referente a pago de acreencias laborales (lo cual evidenciaría el incumplimiento del pago de beneficios) lo que traería como consecuencia igualmente que se dificulte o impida el cobro de beneficios sociales vigentes e impagos, una clara simulación o fraude empresarial con el ánimo de evadir responsabilidades (por ejemplo el caso de que un empleador transfiera su patrimonio y sus trabajadores a una nueva empresa pero que deje en la primera las deudas laborales de estos) o quizás redefinir incumplimientos de pago laborales a la luz del principio de inmediatez o cercanía entre otros más que se pueden pensar pero que lamentablemente no han sido detallados en la norma ni por la construcción jurisprudencial. 
Sea como sea lo que se presente es necesario poner límites claros a la aplicación del criterio de que toda deuda es perseguible y esto obviamente establecer casuísticamente (es decir analizar cada caso en concreto) porque de no presentarse los supuestos descritos por ejemplo o no evidenciarse algún factor de atribución que denote la intención de evasión o peligrosidad en el cobro de las acreencias estimamos coincidiendo nuevamente con el criterio de nuestro respetado profesor - que no resultaría viable que se aplique la Persecutoriedad; en suma debería comprenderse o activarse este derecho a todos los supuestos donde se constate una intención de evasión (aspecto subjetivo) o una situación de riesgo (aspecto objetivo) que impida el pago de beneficios sociales, aquellas situaciones que este fuera de estos criterios no activarían la posibilidad de perseguir el bien, razonamiento que deberá de realizarse desde una óptica protectora y dinámica. 


\section{CAPITULO III: LA RESPONSABILIDAD DE LA EMPRESA PARCIALMENTE ESCINDIDA Y LA BENEFICIARIA vS ACREENCIAS LABORALES: ¿QUE PREVALECE?}

\section{1.- Hacia un control difuso de la protección del crédito laboral}

Ya hemos mencionado en el capítulo anterior que en diversos sistemas jurídicos suelen presentarse un ordenamiento que busque prevenir, fiscalizar o afrontar eventuales maniobras de ciertos empleadores que suscriben una serie de contratos para deshacerse de sus bienes y por consecuencia tratar de evadir sus obligaciones laborales para con sus trabajadores, en no escasos intentos de bordear la Ley imperante, ya hemos manifestado que en nuestra legislación se ha diseñado con dicha finalidad de proteger el crédito laboral el Decreto Legislativo $N^{\circ} 856$ en el cual se señala que la preferencia o prioridad del crédito laboral se ejerce con carácter persecutorio sobre los bienes del negocio, mecanismos diseñado por el legislador que brota del propio artículo $24^{\circ}$ de la Constitución Política (analizado en el capítulo anterior); sin embargo, no es menos cierto que su estructura y delimitación taxativa a exclusivamente los supuestos contenidos en sus artículos 3 y 4 generó encendidos debates en la doctrina y sobre todo teniendo en cuenta la variedad de casos que se suscitaban y que escapaban al listado cerrado creado por el legislador como supuesto que activa este beneficio.

Este diseño normativo, insuficiente para un sector de la doctrina con una posición más paternalista y protectora de la parte trabajadora encuentra su contraparte en aquella posición doctrinal que propugna de igual forma la importancia de la seguridad jurídica al limitar los supuestos en una lista cerrada y por ende no estar sometidos a una aplicación antojadiza de este mecanismo; sin embargo, en este contexto ha sido precisamente la jurisprudencia quien ha desempeñado un rol sumamente activo en la configuración de la garantía constitucional de la Persecutoriedad, en algunos casos interpretando los supuestos descritos en el citado Decreto Legislativo $\mathrm{N}^{\circ} 856 \mathrm{y}$, en otros, aplicando un control de constitucionalidad de la misma. 
Es así entonces que nuestros Jueces se han decantado desde hace varios años ya no solo en limitarse a realizar una interpretación de los supuestos contenidos en la Ley para activar la Persecutoriedad, sino que insistimos desde hace varios años ha propugnado que los supuestos de persecutoriedad no deben limitarse a los casos que aparecen citados en el multicitado Decreto Legislativo, sino que haciendo un control difuso de constitucionalidad de las leyes, lo ha inaplicado, y dispuesto la aplicación del crédito persecutorio en otros supuestos argumentando que en estricta armonía con el segundo párrafo del artículo $24^{\circ}$ de la Constitución, la prioridad en el pago de las remuneraciones y beneficios de los trabajadores no establece limitación o condición alguna previa para que puedan ver satisfechos sus créditos en forma preferente a otros acreedores y por lo tanto las condiciones establecidas en el Decreto Legislativo $\mathrm{N}^{\circ} 856^{\circ}$ en sus artículos $3^{\circ}$ y $4^{\circ}$ no han sido previstas por el legislador constituyente resultando incompatible con las limitaciones establecidas mediante dicha ley e incompatible con lo normado en la Constitución. Posición imperante hasta la actualidad y que ha sido de aceptación total a nivel de la jurisprudencia y que consideramos correcta (aunque con algunas salvedades que ya hemos dicho en el capítulo anterior) interpretación constitucional de citado dispositivo que resulta necesario tener en cuenta y en claro para poder abordar los siguientes puntos materia de análisis.

\section{2.- La Jurisprudencia como fuente del derecho}

Existen diversos autores y ordenamientos jurídicos que tienen categorías diferentes sobre las fuentes de derecho, por lo que, en algunos casos son más amplios y otros más restrictivos. Ahora bien, en sentido estricto el concepto de fuente del derecho se refiere a los orígenes del derecho, los cuales, están íntimamente relacionados a la elaboración y/o producción de las reglas que regulan las relaciones de la vida social.

En ese sentido, la doctrina está de acuerdo que exista una fuente primaria y una fuente secundaria del derecho. Así, por ejemplo, para el sistema del derecho romano germánico (al cual pertenece el Perú) la Ley es la fuente principal de Derecho, siendo sus fuentes secundarias la costumbre y los principios generales del Derecho. Del mismo modo, la jurisprudencia complementa al ordenamiento jurídico a través de la interpretación de la ley, la costumbre y los propios principios generales del Derecho. La jurisprudencia, por regla general, no es fuente directa, sino indirecta de Derecho. 
El precedente judicial (Jurisprudencia o doctrina jurisprudencial o criterio jurisprudencial) es la decisión del tribunal o colegiado más importante del sistema judicial de un país que, al resolver un caso concreto, establece un principio o doctrina jurídica vinculante para el propio tribunal supremo y para todos los órganos jurisprudenciales inferiores, mientras no sea derogada o modificada por resolución debidamente motivada del propio tribunal supremo.

En un sentido más amplio se entiende por jurisprudencia a toda decisión emanada de una autoridad judicial o administrativa, independientemente de su rango y categoría, al interpretar, ejecutar, y aplicar el Derecho a un caso concreto. Así, por ejemplo, en nuestro ordenamiento jurídico hablamos de jurisprudencia de la Corte Suprema, jurisprudencia de la Corte Superior, jurisprudencia del Tribunal Fiscal, del Tribunal Registral, entre otros.

En nuestro país, el ordenamiento jurídico incorpora al precedente judicial o stare decises como fuente formal de Derecho. La creación del Derecho debe ser la obra conjunta del legislador y el juez, puesto que el legislador dicta la ley, pero ésta no opera por si sola, sino a través del juez, quien, mediante la interpretación, establece su sentido con relación a un hecho concreto sometido a su decisión, interpretación que servirá de fundamento para la solución de otros casos futuros iguales, de tal modo que éstos no tengan respuestas jurídicas contradictorias. Desde esta perspectiva, como no puede ser de otra forma, nuestro ordenamiento jurídico establece los casos en que los tribunales encargados de administrar justicia crean precedentes o doctrina jurisprudencial vinculante y en algunos casos (como el del tribunal constitucional) pueden o no ser vinculantes sin embargo, ello no quita o desmerece a su contenido como interpretación para que sirva de fundamento indispensable para resolver casos futuros semejantes y de este modo crear una justicia predecible para que el juez no sea solo "la boca de la ley". $\underline{9}$

\subsection{1.- Evolución de los Criterios Jurisprudenciales sobre acreencias laborales}

Existe muchísima casuística que ha nutrido la Jurisprudencia a lo largo de los años y en la cual se ha evidenciado el arraigo bastante añejo de parte de nuestra legislación de privilegiar los créditos laborales, es así que podemos encontrar variados

\footnotetext{
9 TORRES VASQUEZ, Aníbal. En "La Jurisprudencia como fuente del Derecho" fuente electrónica ubicada en la URL: http://www.etorresvasquez.com.pe/La-Jurisprudencia.html.
} 
pronunciamientos que sin ánimo de hacer una cronología histórica de cada pronunciamiento evacuado por nuestra Corte Suprema o Tribunal Constitucional si conviene traer a colación algunos sustanciales pronunciamientos que han marcado la evolución de dicho privilegio por sobre otras obligaciones así como el carácter persecutorio de la deuda laboral a la luz de determinados principios y normativas que nos van a poder dejar claros visos de cómo ha ido edificándose el criterio de nuestros tribunales a lo largo de los años.

Conviene empezar citando que ya se puede encontrar pronunciamientos que han otorgado prioridad al pago de los créditos laborales en forma concreta desde inicios de la década pasada así tenemos Casación 281-2001-LIMA, de fecha 12 de junio de 2001 que nos decía:

Tercero: Que la acción persecutoria tiene por finalidad apremiar los bienes del empleador o empresario deudor, pues estos constituyen la garantía para el pago de las acreencias laborales. No se trata de identificar quién o quiénes ejercen actualmente la posesión de la empresa originaria, o si hay un vínculo familiar o personal de los terceros adquirentes con el empleador; lo que se trata es de identificar los bienes, tener la certeza de que pertenecieron al empleador deudor y, eventualmente, realizarlos.

En la misma línea, la Sala de Derecho Constitucional y Social de la Corte Suprema, en el Expediente $N^{\circ}$ 851-2001-Lima, nos dice:

Que, en lo concerniente al carácter preferente de los adeudos laborales, su naturaleza reposa en el hecho de que la relación laboral genera una vinculación de tipo personal y además patrimonial entre el trabajador y el empleador. La primera será referida a las condiciones laborales, mientras que la segunda, es una garantía que vincula el patrimonio del deudor al cumplimiento de las obligaciones convencionales y legales (...) que, la acción persecutoria tiene por finalidad apremiar los bienes del empleador o empresario deudor, pues estos constituyen la garantía para el pago de las acreencias laborales. No se trata de identificar quien o quienes ejercen actualmente la posesión de los bienes de la empresa originaria, o si hay algún vínculo familiar o personal de los terceros adquirientes con el empleador; de lo que se trata es de identificar los 
bienes, tener la certeza de que pertenecieron al empleador deudor $y$, eventualmente, realizarlos. $\underline{10} \mathrm{El}$ subrayado es nuestro.

Con el pasar del tiempo vemos que la Corte Suprema ratifica la prioridad en el pago de los créditos laborales eso se evidencia de la Casación 1787-2002-LA LIBERTAD, publicada el 31 de agosto de 2004 que nos informa:

Segundo.- La sentencia de vista, revocando la de primera instancia, declara fundada la demanda de tercería preferente de pago interpuesta por don Carlos Manuel Urquiaga Vega considerando que el artículo 24 de la Constitución Política del Estado es un dispositivo de jerarquía superior a cualquier otra norma legal vigente en nuestro país, resultando aplicable al caso de autos, sin interesar si el derecho del demandado Banco del Nuevo Mundo Sociedad Anónima Empresa Multinacional Andina en liquidación se encuentre registrado, pues un derecho de carácter laboral siempre va a tener preeminencia frente a cualquier otro. Tercero.- Los requisitos que establece el artículo 3 del Decreto Legislativo 856, para la preferencia o prioridad de los créditos laborales, se refieren al carácter persecutorio respecto de los bienes del negocio, sin embargo el artículo 2 de ese mismo Decreto señala expresamente que los créditos laborales tienen prioridad sobre cualquier otra obligación del empleador.

Criterio que se mantuvo durante la vigencia de dicho colegiado así lo podemos verificar de la Casación N²335-2003-LAMBAYEQUE del 10 de noviembre del 2004, que siguiendo el mismo razonamiento del privilegio del crédito laboral estableció:

Quinto.- Pues bien, el Art. 24 de la Constitución establece, en su segundo párrafo, que "el pago de la remuneración y de los beneficios sociales del trabajador tienen prioridad sobre cualquier otra obligación del empleador". Es decir, que dicha norma constitucional no establece ningún requisito o condición previa para que los trabajadores sean pagados de manera preferente a otros acreedores. Sin embargo, el D. Legislativo $N^{\circ} 856^{\circ}$, en sus artículo 3 y 4 , establece condiciones no

10 Términos en los cuales asimismo, se basó la Sala Civil Transitoria de la Corte Suprema al expedir pronunciamiento en la Casación $\mathrm{N}^{\circ}$ 341-2001-Lima y la Sala de Derecho Constitucional y Social Transitoria de la Corte Suprema de Justicia de la República en la Casación N ${ }^{\circ}$ 1303-2003 Lambayeque (publicada en el Diario oficial El Peruano el 30 de noviembre de 2004) 
previstas por el legislador constituyente, es decir, el contenido del citado decreto resulta incompatible con lo normado en la Constitución. $\underline{\mathbf{1 1}}$

Posteriormente, pero manteniendo la misma línea con un leve bajón en su intensidad, en un proceso de tercería preferente de pago iniciado por trabajadores contra un acreedor hipotecario del empleador, la Corte Suprema, en la Casación 2862-2006 LAMBAYEQUE, publicada el 02 de octubre de 2007, citando textualmente al profesor Toyama Miyagusuku, ha expresado lo siguiente:

Duodécimo.- (...) En este escenario [concurso de acreedores del empleador], no resulta relevante que el crédito laboral sea anterior o posterior a uno de naturaleza civil (por ejemplo, un crédito comercial) o que se encuentre inscrito en un registro público (como ocurre con la hipoteca), lo más importante es que nos encontremos ante un trabajador que tiene adeudos de carácter laboral (...); Décimo Cuarto.- (...) [D]e tal manera que el crédito laboral tiene preferencia sobre la acreencia civil más antigua y pública (como puede ser una hipoteca) (...) el crédito laboral debe ser protegido, puesto que estamos ante acreedores más débiles, con un poder de información reducido y los créditos tienen carácter de alimentario y esencial para el trabajador. En tanto no exista un sistema que tutele al personal (como un fondo de garantía salarial) no resulta posible que el crédito laboral ceda ante uno civil (...).

Cabe mencionar en este punto que con ocasión de la Casación $\mathrm{N}^{\circ}$ 932-2002LIMA de fecha 06 de Mayo del 2005, se estableció un interesante criterio a tener en cuenta hasta ese momento no tocado por nuestros tribunales pero que lanza una alerta a los empresarios, hasta ese momento indiferentes a estos criterios ${ }^{12}$ esto es la relación entre persecutoriedad y solidaridad, en dicha sentencia se estableció la obligación solidaria entre dos empresas para asumir el pago de los beneficios sociales de los trabajadores tanto por la naturaleza persecutoria de los derechos laborales, como por la

\footnotetext{
${ }^{11}$ En este punto podemos evidenciar una tendencia más protectora del crédito laboral, ampliando incluso el carácter persecutorio de los créditos laborales a supuestos diferentes a los contenidos en la Ley, lo que nos atrevemos a decir fue la época donde el "péndulo proteccionista" alcanza su mayor altura, época donde vigorosamente se estableció como criterio imperante la persecución casi automática de todos los créditos laborales.

${ }^{12}$ Recuérdese conforme puede revisarse que hasta ese momento el carácter persecutorio había entrado en discusión ante casos de cierre o liquidación de una empresa o en supuestos de concurrencia de acreedores laborales y otros de diferente rango, pero no ante supuestos de sucesiones empresariales o de reorganización de sociedades.
} 
existencia de vinculación económica, si una de ellas es propietaria de las acciones y del inmueble en el que desarrolla sus actividades la segunda.

Hasta aquí podemos evidenciar que la jurisprudencia se ha inclinado por realizar una interpretación amplia del privilegio del crédito laboral; sin embargo, también van deduciendo razonamientos que evidencian que tal derecho no es ilimitado sino que como en los casos presentados deben de concurrir ciertos requisitos, la certeza del crédito laboral y la ausencia de bienes libres del empleador. $\underline{\mathbf{1 3}}$

Sobre el primer requisito, la Corte Suprema ha manifestado en la Casación 17332005 SANTA, publicada el 01 de agosto de 2006 lo siguiente:

Tercero: Que, no hay ninguna duda que los créditos laborales tienen preferencia, porque así lo establece la Constitución y la ley; pero esas preferencia[s] se refieren a créditos laborales ciertos, cuya existencia, legitimidad y cuantía ha[n] sido debidamente acreditadas, lo que requiere que el juzgador compruebe los elementos que configuran la relación laboral previa: como son libros y registros de planillas de remuneraciones, boletas de pago, pagos de aportaciones a la seguridad social y desde luego la existencia del centro laboral. De otro modo, se estaría creando la posibilidad de simulaciones de créditos, en fraude de derechos legítimamente constituidos. (...) Séptimo: Que, en el proceso de tercería preferente de pago, el Juzgador debe determinar la legitimidad y efectividad de los créditos, y luego proceder a su graduación, lo que igualmente importa una labor de apreciación probatoria, que tampoco se ha hecho, y es admisible la defensa sustentada en la connivencia y malicia entre el tercerista [trabajadores] y el demandado [empleador], como aduce el Banco recurrente [acreedor hipotecario] (...). Por eso, el Juez de mérito, al resolver, debe pronunciarse en forma expresa sobre esa argumentación de defensa.

En cuanto al segundo requisito, la Corte Suprema a través de la Casación 44752007 LA LIBERTAD, publicada el 31 de marzo de 2008, refiriéndose al supuesto previsto en el artículo 4 del Decreto Legislativo 856, pero aplicable, en nuestra opinión, a cualquier situación de prioridad laboral, ha sentado el siguiente criterio:

${ }^{13}$ En esta etapa podemos decir que el que hemos denominado "péndulo proteccionista" se contrae y comienzan a limitarse la activación del carácter persecutorio de la deuda laboral de forma automática. 
Séptimo.- Que, además, en el específico caso de autos, las instancias de mérito han logrado establecer que los deudores demandados cuentan con otros bienes susceptibles de ser afectados a fin de garantizar el cumplimiento del pago del crédito laboral del cual es titular el demandante. Siendo así, no existe justificación alguna para que el actor embargue las cuentas de los deudores demandados que se encuentran destinadas al cumplimiento de otras obligaciones, pues existen otras fuentes de ingresos que pueden garantizar el cumplimiento del crédito laboral mencionado en la demanda.

De igual manera nuestro supremo intérprete de la Constitución también se ha pronunciado respecto al alcance del segundo párrafo del artículo 24 de la Constitución. En efecto, en un razonamiento que compartimos si la propia Constitución ordena que el pago de la remuneración y de los beneficios sociales debe tener prioridad sobre cualquiera otra obligación del empleador, entonces resulta imperativo (y por lógica consecuencia) que la misma constitución o la Ley establezca garantías de cobro efectivas, a fin de impedir que los créditos queden impagos por un actuar ilegal del empleador. Es por ello que en esta posición asumida como defensor máximo de la Constitución el Tribunal Constitucional entienda que el segundo párrafo del artículo 24 de la Constitución exige maximizar la posibilidad de que el trabajador cobre sus créditos laborales, finalidad a la que responde directamente la garantía de la Persecutoriedad de los bienes del negocio del empleador y así encontramos frondosos pronunciamientos por citar algunos por ejemplo la STC de fecha 18 de Diciembre del 2007 recaída en el expediente $\mathrm{N}^{\circ} 00122-2007-\mathrm{PA} / \mathrm{TC}$, proceso de amparo seguido por el Banco de Crédito del Perú, ha señalado que:

Que, en tal sentido y a partir de los fundamentos reseñados en el fundamento precedente, el Juez a quo determinó que en el caso resulta de aplicación el artículo 3.b), así como el artículo 4 del Decreto Legislativo 856, que desarrolla el artículo 24 de la Constitución, en el sentido de dar preferencia al cumplimiento de los créditos laborales; de otro lado, debe tenerse presente lo dispuesto en el artículo 26.2 de la propia Constitución, en cuanto al carácter irrenunciable de los derechos reconocidos en la Constitución y la ley, por lo que es posible la existencia de acciones persecutorias, de parte del trabajador, incluso 
cuando el empleador haya transferido la propiedad o los activos de la empresa a terceros, para evadir sus obligacionesfrente a los trabajadores, como ocurre en el proceso de autos.(...). Ello sin perjuicio de las acciones legales que corresponda al Banco contra la referida empresa, como consecuencia de la ejecución de la referida decisión judicial que, eventualmente, hubiere lesionado derechos de contenido patrimonial.

En la misma línea tenemos la STC de fecha 27 de febrero de 2008 recaída en el expediente 3072-2006-PA/TC, que nos informa:

Debemos tener en cuenta que el artículo 24 de la Carta Política del Estado señala que el pago de la remuneración y de los beneficios sociales del trabajador tiene prioridad sobre cualquiera otra obligación del empleador, lo que significa que se debe brindar máxima protección a los derechos fundamentales del trabajador para el cobro de sus acreencias laborales que le posibiliten la satisfacción de sus necesidades humanas primordiales $y$, con ello, tener una subsistencia y vida digna[s] acorde con lo prescrito en el artículo $2^{\circ}$ inciso 1) de nuestra Constitución (...). $\underline{14}$

Conforme a lo expuesto entonces tenemos que nuestros tribunales han ido construyendo su tesis en lo que el legislador ha diseñado como mecanismo de protección de los créditos laborales que brota del propio artículo 24 de la Constitución. Por consiguiente, no estamos ante una mera garantía legal, sino ante una verdadera garantía constitucional conformante de la prioridad laboral señalada por el artículo 24 y que es el razonamiento que ha orientado todos los pronunciamientos citados y que nos sirven para marcar el razonamiento que han venido realizando los Jueces a lo largo de los años.

\footnotetext{
${ }^{14}$ Es necesario precisar que no estamos de acuerdo con el propósito para el que fue utilizado este argumento en la sentencia (creación jurisprudencial de un nuevo plazo de prescripción laboral, de forma que el trabajador tenga un plazo mayor al de 4 años, establecido por la Ley 27321, para cobrar judicialmente sus beneficios sociales, si es que primero decide demandar la nulidad de su despido). Sin embargo, vale lo afirmado por el Tribunal para demostrar que la garantía de la Persecutoriedad tiene una sólida base constitucional.
} 


\subsection{2.- Actual posición de nuestros tribunales sobre el privilegio laboral, su} carácter persecutorio frente a reorganización de sociedades (escisiones) que afecten a las primeras y su responsabilidad

Conforme hemos expuesto, el "péndulo protector" de las máximas instancias de nuestro país, llámese Corte Suprema, así como por el Tribunal Constitucional, manteniendo una sólida posición respecto al privilegio laboral en todo su desarrollo jurisprudencial ( $s i$ bien en algunos años creemos de forma excesiva) ha marcado hitos importantes que se conservan hasta la actualidad con algunas matices que deben ser observadas; en este orden de ideas entonces podemos manifestar que la posición actual de los tribunales (manteniendo criterios de antaño) expresa que la garantía de la persecutoriedad debe ser interpretada en forma amplia en estrecha coherencia con la idea de una efectiva prioridad en el pago de los créditos laborales y con su propia jerarquía constitucional, de igual forma se predica la solidaridad en el pago de beneficios sociales entre empresas vinculadas económicamente con respecto a créditos laborales que mantenga una de ellas, no obstante cada una de las empresas tenga autonomía y personalidad jurídica propia en razón a que en el ámbito laboral se le reconoce una relevancia unitaria $\underline{15}$ y finalmente - pero por ello no menos importante - es que su posición vigente sobre la responsabilidad de obligaciones laborales ante casos de reorganización de $\underline{\text { sociedades es que el nuevo empleador es responsable por las obligaciones laborales }}$ de la empresa escindida en una posición que pone en entre dicho artículos expresos como el que se estudia en el presente trabajo, específicamente ante casos de escisiones por cuanto así lo ha indicado la Corte de Suprema de Justicia de la República en la sentencia recaída en el expediente P.A. No 2310-2011-Ica, en la cual la Corte Suprema nos afirma:

En el acuerdo de escisión parcial sin extinción la empresa beneficiada con el bloque patrimonial de activos y pasivos asume todas las obligaciones laborales que le corresponden a la empresa escindida respecto a los trabajadores que a la fecha fijada para la escisión figuren en la planilla. El subrayado en nuestro.

En este sentido, la Corte Suprema concluyó:

\footnotetext{
15 O como nos dice Toyama: "Como si se tratara de una sola empresa con pluralidad de empresarios, regida por el principio de la responsabilidad solidaria entre todos sus miembros". TOYAMA MIYAGUSUKU, Jorge. "Instituciones del Derecho Laboral”. Gaceta Jurídica, Lima, 2004, pp. 364.
} 
Que esta conclusión es conforme con el artículo 389 de la Ley General

de Sociedades, según el cual, desde la fecha de entrada en vigencia de la escisión, las sociedades beneficiarias responden por las obligaciones que integran el pasivo del bloque patrimonial que se les ha traspasado o han absorbido por efectos de la escisión. El subrayado en nuestro.

Como se puede observar de la citada jurisprudencia, la Corte Suprema hace una desmedida protección a los créditos laborales de los trabajadores, estableciendo que la empresa beneficiaria de un bloque patrimonial no solo se haga responsable de los créditos laborales que correspondan al referido bloque patrimonial (o hasta su valor), sino, incluso de los que existan en la empresa escindida.

En atención a ello, consideramos que los Tribunales de Justicia, amparándose en el principio de persecutoriedad de los créditos laborales, hacen una interpretación antojadiza del artículo $389^{\circ}$ de la Ley General de Sociedades, por cuanto, hacen responsable(s) (de forma solidaria y sin ningún tipo de limitación) a la(s) empresa(s) beneficiaria(s) de todas las obligaciones laborales (créditos laborales) que existan en la empresa escindida, supuesto que no sólo no está regulado en la mencionada norma, sino, que es contrario a ella.

En efecto, según lo dispuesto en el artículo 389 de la Ley General de Sociedades, la sociedad beneficiaria es responsable únicamente de las obligaciones que integran el pasivo del bloque patrimonial que se les ha traspasado o han absorbido por efectos de la escisión, es decir, en ningún extremo de la citada norma, la empresa beneficiaria debe hacerse responsable más allá de los pasivos que integran el bloque patrimonial (insistimos, o su valor).

Así, esta posición jurisprudencial vigente que observamos amplía en forma desmedida la posibilidad de activar el privilegio de la persecutoriedad del crédito laboral así viene relacionando (creemos indebidamente) conceptos como responsabilidad solidaria en función a la persecutoriedad de los créditos laborales y finalmente creemos que devalúa el espíritu normativo contenido en el artículo $389^{\circ}$ de la Ley General de Sociedades, quizás, por una insuficiente regulación en lo referente a la responsabilidad de las sociedades partícipes en una reorganización de este tipo, lo que hay que analizar minuciosamente porque este activismo puede resultar (si es que no viene siéndolo ya) contrario al bien jurídico constitucional de la seguridad jurídica. 


\section{3.- Impacto económico en las empresas intervinientes en el proceso de escisión: cuando la espada de Damocles cae.}

En atención al criterio jurisprudencial referente al carácter preferente del pago y a la persecutoriedad de los créditos laborales creado por la Sala de Derecho Constitucional y Social de la Corte Suprema de Justicia y el Tribunal Constitucional, válidamente podemos señalar que éste viene generando un impacto negativo en el ámbito de las operaciones financieras y en las transacciones comerciales que se desarrollan en nuestro país.

Si bien este privilegio puede afectar a muchas esferas nos interesa sobre todo saber el impacto económico que podría traer la aplicación del carácter persecutorio de cara a reorganización de sociedades específicamente ante una escisión, la cual conforme a su texto regulatorio de la Ley General de Sociedades pareciera ser sumamente claro; sin embargo, tenemos que se vuelve turbio cuando estamos ante este tipo de acreencias laborales.

Con todo lo ya explicado hasta ahora referente a la responsabilidad de la sociedad escindida y la beneficiaria de acuerdo a la Ley General de Sociedades, así como a las características y privilegios que ha dotado la Ley a los créditos laborales podemos advertir que se han generado sendos problemas en aquellos casos en los que ha existido una trasferencia de bienes a otra empresa (como en el caso de escisión) $\underline{\mathbf{1 6}}$ en la que mayoritariamente se ha dejado de lado lo prescrito en el artículo $389^{\circ}$ de la Ley General de Sociedades, castigándose a la sociedad beneficiaria sin hacer mayor análisis o evaluación del caso en concreto, lo que vacía de contenido el fundamento de dicho dispositivo; sin embargo, si bien sabemos existe una casta empresarial con una vocación netamente evasiva y con fines contrarios a los que inspiraron esta forma de reorganización de sociedades creemos que es necesario poner un freno a un uso desmedido del privilegio establecido por la Constitución de los créditos laborales; en este sentido, y sin tratar de desentrañar la validez o buena fe de quien realizo la escisión o su ánimo evasivo tenemos que dicha interpretación condiciona directamente la

\footnotetext{
${ }^{16}$ Recordemos que para el Decreto Legislativo No 856 la acción persecutoria procede: ii) sobre los bienes que transfiera a terceros o que aporte para la constitución de una nueva empresa, aquel empleador que hubiera extinguido la relación laboral con su personal e incumplido las obligaciones laborales por simulación o fraude a la Ley, mediando una injustificada disminución o distorsión de la producción que provoque el cierre del centro de trabajo o su abandono
} 
seguridad jurídica en la transferencia de bienes y ha permitido que por una lamentable casta empresarial otros con honorables motivos de inversión padezcan la aplicación muchas veces injustificada de este privilegio; precisamente, porque el "superprivilegio" que nuestra Constitución Política asigna al crédito laboral, el Decreto Legislativo $\mathrm{N}^{\mathrm{o}}$ 856 le concede carácter persecutorio. En mérito a aquel, el acreedor laboral podrá hacer efectivo su crédito incluso sobre bienes que pese a haber pertenecido a su empleador, se encuentran en posesión o son de propiedad de un tercero (como podría ser el caso de una sociedad beneficiaria de una escisión) y por consecuencia afectarlos, gravarlos e incluso realizarlos para el cobro de las mismas. Ahora bien, aunque es claro que las operaciones de transferencia que se realicen con propósito fraudulento deben ser ineficaces frente a los acreedores laborales $\underset{17}{ }$, la inexistencia de un parámetro temporal y/o criterios objetivos que ayude a delimitar este supuesto ha derivado en una construcción jurisprudencial que afecta con la persecutoriedad cualquier tipo de transacciones, sin importar el momento en el que ocurrieron, si estas obedecen a operaciones regulares y por último, si en ellas existía intención de fraude, lo que innegablemente ha propiciado un contracción en la voluntad inversionista.

En este escenario, tenemos entonces que el impacto económico en negativo para una empresa beneficiaria de una escisión aparece en dos momentos, el primero porque encarece los costos de transacción en las operaciones propias y habituales del sector empresarial (compraventa, arrendamiento, fusiones, escisiones, etc.), pues hoy termina siendo imprescindible un due diligence laboral previo que ayude (y decimos ayude o trate de minimizar) a determinar si existe deuda laboral e identificar eventuales contingencias. Pese a que esta práctica no elimina el riesgo, sí lo atenúa y a su vez, lo que incide directamente en otro aspecto del negocio pues normalmente cuando un riesgo es mayor o no cuantificable se opta por castigar el precio midiéndolo y ajustándolo no al valor del precio o contraprestación respectiva en la transacción sino en función a costear la posible contingencia siempre latente (más aún cuando existe traspaso de mano trabajadora). Conforme a lo expuesto entonces puede pasar que una empresa que pretenda escindir una parte de su línea para una mayor rentabilidad al asociarse con otra líder en el rubro no lleguen a concretizar el negocio porque para la segunda resultaría

\footnotetext{
${ }^{17}$ Lo que en si constituye el freno para aquello empresarios con vocación fraudulenta o que realizan estos tipos de operaciones solo con la intención de burlar la Ley y dejar impagos derechos laborales y que debemos manifestar estamos completamente de acuerdo la aplicación de este principio ante esos casos.
} 
riesgoso aquella transferencia de bienes o quizás aprovechándose de dicha situación castigue demasiado el valor de la operación en su beneficio haciendo económicamente inviable dicha operación para la primera y por consiguiente postergando una posibilidad de inversión.

En el segundo momento nos referimos a aquella en la que la sociedad beneficiaria de una escisión podría o es víctima precisamente de un desmedro en su patrimonio por el carácter persecutorio de las deudas laborales de la empresa escindida a pesar de que el artículo $389^{\circ}$ de la Ley General de Sociedades establece claramente los límites de la responsabilidad de la misma una vez entrada en vigencia la escisión; en efecto nadie puede negar que existen muchos procesos laborales que en etapa de ejecución de sentencia pretenden la ejecución de bienes que fueron transferidos a terceros, quienes adquirieron de buena $f e$, ya que, la transferencia de dichas propiedades se debe a una operación regular y ejecutada muchos años antes de que el acreedor laboral exista como tal, esto es, antes que se extinga la relación laboral con el trabajador (acreedor laboral) y aquel inicie la acción judicial para el cobro de dicha acreencia laboral, e incluso, existen casos que el Juez no toma en cuenta o revisa si el deudor-empleador cuenta con otros bienes que, igualmente, pueden garantizar el pago de la deuda. Así por ejemplo, tenemos el caso de un proceso laboral que inició el ex trabajador de una empresa pesquera, en el que, el Juez autorizó que el pago de la deuda laboral se efectué con el remate de una embarcación pesquera, aun cuando dicho bien había sido aportado a un fideicomiso en garantía que aún se encontraba vigente. Asimismo, en otro caso, el Juez autorizó que el pago de la deuda laboral se realice con el remate de un bien inmueble que no era (y nunca lo fue) de propiedad del deudor, ya que, dicha propiedad lo obtuvo mediante un arrendamiento financiero que resuelto y ejecutado por incumplimientos de sus obligaciones.

Así, se genera situaciones en muchos casos en donde se le afectan los bienes adquiridos de buena fe por terceros y que ocasionan claramente un severo perjuicio económico a la empresa beneficiaria, sino revisemos el ejemplo dado, una embarcación pesquera para una empresa de dicho rubro que recién comienza podría determinar la quiebra de la misma y tirar por la borda toda una inversión que bien podría haber generado divisas y hasta más empleo. 
En resumen, lejos de aplicar la persecutoriedad solo frente a la inviabilidad de apremiar los propios bienes del empleador-deudor originario, existe una reiterada tendencia a aplicarlo sin más, omitiendo analizar si existió o no fraude. Lo que indudablemente distorsiona la finalidad del "derecho persecutorio" y como corolario, resta seguridad al tráfico jurídico de bienes, a pesar de que aparentemente existen límites claros establecidos en la Ley General de Sociedades.

\section{4.-Nuestro Planteamiento para una aplicación coherente de la responsabilidad de} la empresa parcialmente escindida y la beneficiaria frente al carácter persecutorio de la deuda laboral

Como ya se puede haber notado, nuestra posición es claramente contraria a una aplicación automática del privilegio persecutorio de la deuda laboral, y si bien no creemos que la posición asumida sea vejatoria de derechos, estamos convencidos de que deben existir límites claros para la aplicación de la misma y la responsabilidad que tendría en todo caso la sociedad beneficiaria de la escisión, en una interpretación coherente y armoniosa con los preceptos constitucionales en juego.

Ya hemos adelantado párrafos atrás que consideramos que resulta prudente poner límites claros a la aplicación del criterio de que toda deuda es perseguible y esto obviamente establecerlo casuísticamente (es decir analizar cada caso en concreto) porque de no presentarse supuestos en los que se pueda establecer un "factor de atribución" en las manifestaciones o rasgos sintomáticos característicos de una evasión laboral, o permitirnos constatar una situación de riesgo de incumplimiento laboral ${ }^{18}$ o no evidenciarse alguna intención de evasión o peligrosidad en el cobro de las acreencias estimamos que no se debería quebrar la regla contenida en el artículo $389^{\circ}$ de la Ley General de Sociedades y por ende no resultaría viable que se aplique la Persecutoriedad del crédito laboral contra la empresa beneficiaria de la escisión y mucho menos trasladarle una responsabilidad casi automática a la misma (como lo

\footnotetext{
${ }^{18}$ Como ya citamos como ejemplos en el capítulo 2: i) El incumplimiento reiterado del empleador en el pago de los beneficios sociales; ii) La existencia de un desprendimiento injustificado del patrimonio de la empresa; iii) La ausencia de bienes adicionales del empleador que permitan garantizar el pago de las deudas laborales; iv) El cierre total o parcial de las operaciones de la empresa; v) La existencia de una elevada carga procesal o demandas en su contra referente a pago de acreencias laborales (lo cual evidenciaría el incumplimiento del pago de beneficios); vi) Una evidente simulación o fraude empresarial con el ánimo de evadir responsabilidades (por ejemplo el caso de que un empleador transfiera su patrimonio y sus trabajadores a una nueva empresa pero que deje en la primera las deudas laborales de estos); etc.
} 
sostiene la Corte Suprema en la sentencia revisada en el Punto 3.3.2); en suma debería comprenderse o activarse este derecho a todos los supuestos donde se constate una intención de evasión (aspecto subjetivo) o una situación de riesgo (aspecto objetivo) que impida el pago de beneficios sociales, aquellas situaciones que estén fuera de estos criterios no activarían la posibilidad de perseguir el bien y menos aún una responsabilidad de la sociedad beneficiaria de la escisión en salvaguarda de la constitucionalidad del artículo $389^{\circ}$ de la Ley General de Sociedades, razonamiento que desde luego debe realizarse desde una óptica protectora, pero sin dejar en consideración el dinamismo económico.

Es claro que necesitamos establecer reglas claras y predeterminadas en nuestro ordenamiento jurídico de la responsabilidad de la empresa beneficiaria frente a la existencia de acreencias laborales, que, no deberían trasladas las que corresponden a la empresa escindida y, mucho menos, que ésta sea ilimitada.

\subsection{1.- Propuesta de Reforma Legislativa}

Sin ánimo de encender polémica y obviamente sin pretender desmerecer los válidos criterios de los iluminados miembros de la comisión que elaboro la Ley General de Sociedades creemos que estando a una utópica predectibilidad en los fallos judiciales, concepto que más parece lírico creemos conveniente que se realicen mejoras o rediseños en la actual normativa, sobre todo teniendo en cuenta los factores que se presentan (empresarios con vocación perversa, protección constitucional de los créditos laborales, protección de la seguridad del tráfico jurídico de bienes y la inversión misma como derecho constitucional de hacer empresa); así revisadas algunas legislaciones, sobre todo Europeas las cuales han servido de fuente en muchas ocasiones y estando a lo subjetivo aún ( $y$ variantes) que son los límites impuestos por nuestra jurisprudencia para determinar la responsabilidad y activar la Persecutoriedad del crédito laboral creemos que resultaría necesario incluir en nuestra legislación una doble medida de protección que aun cuando sean diversas e, incluso, puedan operar sin influirse mutuamente, configuren una técnica principal (oposición) y otra complementaria (responsabilidad) que integren un mismo sistema unitario; o como nos ilustra autorizada Doctrina internacional, como es de Duque Domínguez (2009) que "constituyen a nuestro ver dos medidas complementarias que cierran un único sistema tuitivo" (pp.563). 
Así las cosas proponemos que en salvaguarda de la constitucionalidad y sobre todo para que los tribunales no vacíen de contenido el artículo $389^{\circ}$ de la Ley General de Sociedades, al hacer un control difuso de las normas frente a los preceptos constitucionales laborales, debe ser modificado y añadirse un artículo más, como se detalla a continuación:

Art. 389-A:

Sólo en los casos de créditos laborales, la responsabilidad de la empresa escindida y la empresa beneficiaria es solidaria por las obligaciones incumplidas por la primera siempre y cuando se constate una intención de evasión o una situación de riesgo que impida el pago de beneficios sociales; teniendo la empresa beneficiaria como límite de su responsabilidad hasta un monto máximo el valor económico del bloque patrimonial traspasado.

De los créditos laborales asumidos por una sociedad beneficiaria que resulten incumplidas responderá solidariamente todas las sociedades beneficiarias hasta el importe del valor del activo neto atribuido en la escisión a cada una de ellas y, si subsistiera, la propia sociedad escindida por la totalidad de la obligación.

En los créditos laborales en operaciones que estén fuera de los supuestos descritos en el párrafo anterior y en donde se haya cumplido con el procedimiento contenido en el Art. 383-A. no será de aplicación la responsabilidad solidaria.

De igual manera para que no se afecte la seguridad jurídica y conforme a lo que exponemos resulta necesario una doble protección en ambos sentidos tanto para el acreedor laboral como para el empresario beneficiado con la escisión por lo que se propone también se agregue un artículo más:

Art. 383-A:

Para un mejor ejercicio efectivo del derecho de oposición en el caso de acreedores laborales el aviso al que hace referencia el Artículo 380 
también debe de ser publicado en el mural de su respectivo sindicato de tratarse de empresas que cuenten con uno o varios; de no contar con sindicatos, el aviso también debe ser publicado en un mural que confeccionará para esta exclusiva finalidad la empresa el cual deberá ser colocado en la entrada principal de la misma u otro medio físico, electrónico, digital, etc., donde conste la comunicación efectiva a los trabajadores del acuerdo de escisión adoptada por la empresa. La prueba del aviso o la comunicación corresponderá a la empresa.

Si no existe oposición del acreedor laboral, no será de aplicación el Art. 389-A de la Ley.

Como ya se señaló, consideramos que de esta forma, se podrá proteger doblemente los derechos de los acreedores sociales, una que opere a posteriori; así como un mecanismo que dota al acreedor de una tutela a priori (oposición), la responsabilidad sólo puede hacerse efectiva ex post; es decir, una vez que el proceso escisorio es firme. De este modo, con la responsabilidad de las sociedades beneficiarias de la forma planteada se podría mantener la garantía unitaria que representa el patrimonio de la escindida para sus acreedores tras el fraccionamiento y la distribución de aquél, con el traslado de una mayor diligencia y responsabilidad del primero.

\section{5.- Análisis de un caso a la luz de nuestro planteamiento}

En esta ocasión traemos un caso aún en trámite y de reciente data llevado ante los tribunales de la Ciudad de Pisco en los que existe unas acreencias laborales que ahora el sindicato demandante reclama a la actual empresa en la que trabajan y a la cual pasaron precisamente por una reorganización societaria (escisión) de su anterior empleadora, la sentencia ha sido declarada fundada, reconociendo la obligación y solidaridad en el pago de las acreencias reconocidas por el Indecopi a favor de los trabajadores demandantes a ambas empresas la Fabrica de Tejidos Pisco S.A. (sociedad beneficiaria de la escisión) y la empresa Cotonificio S.A.(Sociedad escindida) por los siguientes considerandos:

\section{SEPTIMO: DE LA ESCISIÓN EMPRESARIAL}

7.1 La Escisión es la fragmentación de una entidad jurídica en dos o más de la misma especie, pudiendo ser de igual o diferente magnitud. Se da la Escisión 
cuando una sociedad denominada Escindente decide extinguirse y divide la totalidad o parte de su activo, pasivo y capital social en dos o más partes, que son aportadas en bloque a otras sociedades de nueva creación denominadas Escindidas; o cuando la Escindente, sin extinguirse aporta en bloque parte de su activo, pasivo y capital social a otra u otras sociedades de nueva creación. La escisión puede tomarse como un recurso para dispersar el objeto social propuesto en un principio por lo socios de una empresa sin llegar a la necesidad de la liquidación patrimonial, todo esto en la eventualidad de que la empresa escindida se encuentre inmersa en alguna causal de disolución o para resolver problemas financieros o administrativos

7.2 La escisión se divide en clases, dentro de ellas la Escisión por Absorción: que se presenta cuando una sociedad, sin disolverse, transfiere parte de su patrimonio a una empresa ya existente. La escisión por absorción es un contrato, celebrado entre las sociedades escindidas y las sociedades absorbentes. Mientras que la Escisión Parcial: se presenta cuando la sociedad escindida se reserva parte de su patrimonio para sí, y transfiere solo una parte del mismo para la creación de una empresa nueva o preexistente.----

7.3 De lo expuesto, debe señalarse que la escisión de empresas tiene efectos en las relaciones laborales que deben ser afrontadas aplicando los principios e instituciones propias del derecho laboral, aspectos que se derivan precisamente del carácter tuitivo de esta disciplina. Así, Américo Plá Rodríguez al desarrollar la figura de la sustitución del empleador como expresión del principio de continuidad refiere que: "La idea directriz es que la empresa constituye una universalidad cuyos elementos pueden cambiar sin que se altere la unidad del conjunto. El empleador puede transferir a otro la empresa, los miembros del personal se renuevan sin que se altere esa unidad. Cuando el nuevo empleador continúa la explotación en las mismas condiciones que su predecesor, la unidad económica y social que constituye la empresa permanece (siendo) la misma." En efecto, en función al principio de continuidad los derechos laborales de los trabajadores de la empresa comprendida en un proceso de escisión, ya sea en la fusión parcial como en la fusión por absorción, se encuentran debidamente resguardados pues el trabajador resulta completamente ajeno a los cambios que se puedan presentar en la organización empresarial o en la titularidad de la 
misma lo cual tiene que ver igualmente con el principio de despersonalización del empleador. En ese sentido la organización empresarial que resulte del proceso de escisión asumirá la responsabilidad respecto a los derechos laborales de los trabajadores. De esta forma, el único caso de exoneración de que goza la empresa absorbente o la nueva organización empresarial creada en virtud de la escisión para evadir el pago de las remuneraciones, indemnizaciones y beneficios sociales peticionados por el trabajador, es aquél en el que la empresa absorbida o extinguida haya cumplido con sus obligaciones conforme a ley.

\section{OCTAVO: DEL CARÁCTER PERSECUTORIO DE DERECHOS}

\section{LABORALES:}

$\underline{8.1}$ El artículo 24 de la Constitución del Estado establece que: “(...) El pago de la remuneración y de los beneficios sociales del trabajador tiene prioridad sobre cualquiera otra obligación del empleador (...).El reconocimiento del carácter preferencial de los derechos laborales también ha sido materia de regulación por los instrumentos internacionales. Así el artículo 11 del Convenio de la OIT $N^{\circ} 95$ prescribe que los créditos laborales tienen preferencia en los casos de quiebra o liquidación de una empresa y deberán ser pagados antes que los acreedores ordinarios. Si bien es cierto este convenio no ha sido ratificado por el Perú, el mismo tiene el carácter de recomendación. No obstante ello, en nuestro ordenamiento legal se ha consagrado no solamente la naturaleza privilegiada de los créditos de origen laboral, conforme lo manda el articulo antes citado, sino además el carácter persecutorio que tienen los beneficios sociales respecto de los bienes del negocio, lo cual además tiene directa vinculación con el principio laboral de despersonalizacion del empleador. El establecimiento de los principios antes indicados tiene que ver con el carácter alimentario que se le otorga a los beneficios sociales de los trabajadores de manera que se considera en la doctrina laboral que debe cautelarse el cobro efectivo de dichos derechos y evitar que los mismos se conviertan en ilusorios por hechos que la legislación se ha encargado de precisar. 
8.2 A ese efecto, articulo 3.b) del Decreto Legislativo $N^{\circ} 856$, establece que la preferencia o prioridad de los créditos laborales se ejerce con carácter persecutorio de los bienes del negocio, " en los casos de extinción de las relaciones laborales e incumplimiento de las obligaciones con los trabajadores por simulación o fraude a la ley, es decir, cuando se compruebe que el empleador injustificadamente disminuye o distorsiona la producción para originar el cierre del centro de trabajo o transfiere activos fijos a terceros o los aporta para la constitución de nuevas empresas o cuando abandona el centro de trabajo"

$\underline{8.3}$ En el supuesto antes citado se encontraría la escisión por absorción, de una persona jurídica, esto es, cuando se aporta activos fijos para la constitución de la nueva empresa, en cuyo caso opera el carácter persecutorio de los beneficios sociales respecto de los bienes aportados. Sin embargo, el carácter preferencial reconocido en la Constitución no puede ser restringido legalmente de manera tal que se afecte los derechos laborales de los trabajadores al constituir un derecho alimentario, que merece protección ante la desigualdad existente frente al empleador, dado el carácter tuitivo del derecho laboral.

\section{NOVENO: DEL ANALISIS DEL CASO CONCRETO:}

\section{(...)}

9.22. Así, examinado el Testimonio de folios 299 a 317, que comprende la Escisión Parcial del Bloque Patrimonial entre la empresa Cottonificio Sur Perú S.A.C. y Fabrica Tejidos Pisco S.A.C., se aprecia que en su punto cuarto, se señala respecto de los activos y pasivos que integran el bloque patrimonial correspondiente a Fabrica de Tejidos Pisco S.A.C., en el numeral 41 (fojas 304 vuelta), que asume las remuneraciones y participaciones por pagar, que comprenden saldos, salarios y vacaciones, a partir del 01 de enero de 2008; en tanto, que con relación a Cottonificio Sur Perú S.A.C. (a folios 305 vuelta), le correspondería pagar todas las remuneraciones que se devenguen y queden pendientes al 31 de diciembre de 2007. Sin embargo, se aprecia de su punto 
quinto y sexto del citado contrato de escisión, (a folios 306 vuelta), que al ser negativo el valor neto del bloque patrimonial, la sociedad beneficiaria no aumentara su capital social ni emitirá nuevas acciones a favor de los accionistas de la sociedad escindida; además que no se afectara el capital social de la sociedad escindida, pero si en cambio su patrimonio neto.

9.23 Debe señalarse, que el Tribunal Constitucional en reiteradas jurisprudencia ha precisado en cuanto a la tutela jurisdiccional efectiva que: “...comprende, entre otra cosas, el derecho a la efectividad de las resoluciones judiciales, es decir que el fallo judicial se cumpla y que al justiciable vencedor en juicio justo y debido se le restituya su derecho y se le compense, si hubiere lugar a ello, por el daño sufrido; y que (...) exige no solo que quienes hayan resultado vencidos en juicio cumplan todos los términos señalados en la sentencia firme, sino también impone deberes al juez y, en particular, a aquellos que están llamados a ejecutar lo resuelto en la sentencia. En particular, la responsabilidad de ejecutarlas, para lo cual tienen la obligación de adoptar todas las medidas necesarias y oportunas destinadas a dar estricto cumplimiento a la sentencia, las que deberán tomarse sin alterar su contenido o su sentido" ${ }^{19}$; de allí que a efectos de no convertir un fallo judicial en un mero pronunciamiento lirico, el juez debe establecer los mecanismos adecuados para la restitución del derecho vulnerado o reconocido, sin que ello signifique la vulneración de otros derechos fundamentales.

9.24 Con relación al debido proceso, el Tribunal también ha señalado que: “...es un derecho fundamental de naturaleza procesal con alcances genéricos, tanto en lo que respecta a los ámbitos sobre los que se aplica como en lo que atañe a las dimensiones sobre las que se extiende. (...) En lo que respecta a lo segundo, y como ha sido puesto de relieve en innumerables ocasiones, las dimensiones del debido proceso no solo responden a ingredientes formales $o$ procedimentales, sino que se manifiestan en elementos de connotación sustantiva o material, lo que supone que su evaluación no sólo repara en las reglas esenciales con las que se tramita un proceso (juez natural, procedimiento preestablecido, derecho de defensa, motivación resolutoria, instancia plural,

${ }^{19}$ STC No01334-2002-AA/TC, fundamento 2 
cosa juzgada, etc), sino también y con mayor rigor, se orienta a la preservación de los estándares o criterios de justicia sustentables de toda decisión (juicio de razonabilidad, juicio de proporcionalidad, interdicción de la arbitrariedad, etc.)

\section{(...)}

9.26. De lo expuesto es prudente indicar que la acreencia concursal reclamada por los accionantes, es una acreencia reconocida por INDECOPI...(sic)...que tiene su origen en deudas laborales, y por tanto son deudas de índole laboral, y por tanto, como se ha desarrollado precedentemente IRRENUNCIABLES, correspondiendo determinar si dicha acreencia laboral, le alcanza, también a Fábrica de tejidos Pisco S.A.C. en virtud del carácter persecutorio de los créditos laborales, en atención de la escisión realizada entre ambas sociedades comerciales

9.27 Al respecto, debe señalarse que la jurisprudencia se ha encargado de establecer la prevalencia de la norma constitucional en aquellos supuestos no previstos en la norma de desarrollo legislativo, en este caso, el Decreto Legislativo $N^{\circ} 856$. Así, mediante Casación $N^{\circ} 2335-2003$ del 10 de noviembre de 2004, la Sala Civil Permanente de la Corte Suprema de la República ha señalado en su quinto y sexto considerando que: "Quinto.- Pues bien, el artículo 24 de la Constitución Política establece, en su segundo párrafo, que 'El pago de la remuneración y de los beneficios sociales del trabajador tiene prioridad sobre cualquiera otra obligación del empleador. Es decir, que dicha norma constitucional no establece ningún requisito o condición previa para que los trabajadores sean pagados de manera preferente a otros acreedores. Sin embargo, el Decreto Legislativo $N^{\circ} 856$, en sus artículos 3 y 4, establece condiciones no previstas por el legislador constituyente, es decir, el contenido del citado Decreto Legislativo resulta incompatible con lo normado en la Constitución. Consecuentemente con lo anterior, la aplicación de los artículos 3 y 4 del Decreto Legislativo 856 importaría la violación de los principios de jerarquía del ordenamiento jurídico, de supremacía de la Constitución y del indubio pro operario, previstos en las normas constitucionales transcritas en el cuarto considerando de esta resolución”. En este mismo sentido en la Casación $N^{\circ}$ 1787-2002 La Libertad, la Corte Suprema ha determinado textualmente que: 
“(...) considerando que el artículo 24 de la Constitución Política del Estado es un dispositivo de jerarquía superior a cualquier otra norma legal vigente en nuestro país, resultando aplicable al caso de autos, sin interesar si el derecho del demandado Banco del Nuevo Mundo Sociedad Anónima empresa multinacional andina en liquidación se encuentre registrado, pues un derecho de carácter laboral siempre va a tener preeminencia frente a cualquier otro".---

9.28 Por otro lado, la Sala de Derecho Constitucional y Social de la Corte Suprema, en el Expediente $N^{\circ}$ 851-2001-Lima, al desarrollar el objeto del carácter persecutorio de los beneficios sociales ha destacado la naturaleza personal patrimonial del crédito laboral, afirmando: "Que, en lo concerniente al carácter preferente de los adeudos laborales, su naturaleza reposa en el hecho de que la relación laboral genera una vinculación de tipo personal y además patrimonial entre el trabajador y el empleador. La primera será referida a las condiciones laborales, mientras que la segunda, es una garantía que vincula el patrimonio del deudor al cumplimiento de las obligaciones convencionales y legales (...) que, la acción persecutoria tiene por finalidad apremiar los bienes del empleador o empresario deudor, pues estos constituyen la garantía para el pago de las acreencias laborales. No se trata de identificar quien o quienes ejercen actualmente la posesión de los bienes de la empresa originaria, o si hay algún vínculo familiar o personal de los terceros adquirientes con el empleador; de lo que se trata es de identificar los bienes, tener la certeza de que pertenecieron al empleador deudor y, eventualmente, realizarlos", términos en los cuales asimismo, se basó la Sala Civil Transitoria de la Corte Suprema al expedir pronunciamiento en la Casación $N^{\circ}$ 341-2001Lima y la Sala de Derecho Constitucional Social Transitoria de la Corte Suprema de Justicia en la Casación N¹303-2003 Lambayeque. Igualmente, mediante la Casación $N^{\circ}$ 885-2001 La Libertad, la Corte Suprema ha establecido que: "Por el derecho de persecución si el constituyente de la hipoteca procede a enajenar el inmueble hipotecado, el acreedor tiene el derecho de perseguir el bien, cualquiera sea su adquiriente, con la finalidad de hacerse pago con el precio que se obtenga en el remate." 
9.29 Finalmente, el Tribunal Constitucional en el expediente $N^{\circ} 00122-2007$ PA/TC, proceso de amparo seguido por el Banco de Crédito del Perú ha señalado: "Que, en tal sentido y a partir de los fundamentos reseñados en el fundamento precedente, el Juez a quo determinó que en el caso resulta de aplicación el artículo 3.b), así como el artículo 4 del Decreto Legislativo 856, que desarrolla el artículo 24 de la Constitución, en el sentido de dar preferencia al cumplimiento de los créditos laborales; de otro lado, debe tenerse presente lo dispuesto en el artículo 26.2 de la propia Constitución, en cuanto al carácter irrenunciable de los derechos reconocidos en la Constitución y la ley, por lo que es posible la existencia de acciones persecutorias, de parte del trabajador, incluso cuando el empleador haya transferido la propiedad o los activos de la empresa a terceros, para evadir sus obligaciones frente a los trabajadores, como ocurre en el proceso de autos.(...). Ello sin perjuicio de las acciones legales que corresponda al Banco contra la referida empresa, como consecuencia de la ejecución de la referida decisión judicial que, eventualmente, hubiere lesionado derechos de contenido patrimonial".

9.30 En ese sentido, en el caso de la escisión parcial por absorción se tratará de identificar los bienes que hubieren pertenecido a la empresa absorbida pudiendo afectarse los mismos en virtud del carácter persecutorio de los derechos laborales respecto de los bienes de su empleador pues si bien hay que distinguir entre el carácter preferencial de los créditos laborales de la realización de los adeudos laborales con el derecho persecutorio, también es cierto que ambos actúan casi de manera inescindible, por cuanto la interpretación sistemática de las normas constitucionales y laborales conllevan el dotar al trabajador de las herramientas jurídicas necesarias a fin de que los derechos laborales reconocidos legalmente puedan concretizarse en la realidad.

9.31 De lo antes expuesto, queda claro que en el presente caso los derechos laborales (saldo del pago de beneficios sociales) del actor tienen carácter persecutorio respecto a la escisión producida entre la empresa Cottonificio Sur Perú S.A.C. con la empresa Fabrica de Tejidos Pisco S.A.C. Si bien es cierto, en la minuta de Constitución de la escisión se ha señalado que la fábrica Tejidos 
Pisco asume los pasivos (sueldos, salarios, vacaciones) relacionado con el pago de remuneraciones y participaciones por pagar a partir del 01 de enero de 2008, así se aprecia de folios 90 vuelta, mientras que la emplazada Cottonificio Sur Perú asumiría todos los pasivos hasta el 31 de diciembre de 2007, así se aprecia de folios 91 vuelta. Sin embargo, no es menos cierto, que de la misma instrumental se aprecia de su punto quinto y sexto, de folios 92 vuelta, que los accionistas de la sociedad escindida no serán favorecidos con nuevas acciones producto de la escisión y que al ser adquirido en negativo el bloque patrimonial escindido no se afectara el capital social pero si su patrimonio neto. De lo que trasciende, que la emplazada Cottonificio Sur, se habría desprendido del total de sus bienes inmuebles y de gran parte de los bienes muebles a favor de Fábrica de Tejidos Pisco, quien al adsorber dicho bloque patrimonial ha dejado en desamparo, en el caso en particular al actor, quien al tener un saldo pendiente de pago, por la primera de las empresas mencionadas, se ve imposibilitado de hacer efectivo su cobro, en tanto que se habría quedado sin bienes inmuebles que permitan asegurar el cumplimiento de la obligación de pago.

9.32 Además, se aprecia de autos que si bien Tejidos Pisco sostiene asume los pasivos desde 01 de enero de 2008, dejando a Cottonificio los pasivos hasta el 31 de diciembre de 2007, ello, no resulta coherente social y empresarialmente, en tanto que al adsorber la primera todo el patrimonio inmueble de la segunda, dejándole a ésta última un pequeño porcentaje y su capital, no tendría como cubrir obligación alguna de los acreedores laborales como en este caso; lo que hace presumir la existencia de un fraude empresarial a efectos de liberarse de sus acreencias laborales; situación que no es permitida por ley ni la Constitución, pues para el efecto le favorece al actor el carácter persecutorio de sus acreencias laborales conforme lo previsto en el Decreto Legislativo $N^{\circ} 856$, que además encuentra sustento constitucional en el principio de irrenunciabilidad de derechos laborales y el carácter tuitivo del trabajador; máxime, si la pretensión del actor es una que está reconocida en forma expresa a través del derecho reconocido por INDECOPI, y que al devenir de un derecho laboral, como es el pago de sus beneficios sociales, que ésta regulado por ley; no puede ser perjudicado por ningún acuerdo empresarial, en tanto que también 
le favorece al actor el Principio de no Regresividad o Irreversibilidad; esto es, la imposibilidad de que se reduzca la protección ya ganada del actor; de allí que en mérito del carácter persecutorio de los créditos laborales la Fábrica de Tejidos Pisco está obligada al cumplimiento del pago del saldo de beneficios sociales del actor

9.33 De otro lado, en cuanto a la Fábrica Cottonificio Sur Perú, debe precisarse que en el Pleno Jurisdiccional Laboral del 2008 se acordó que "Existe solidaridad en las obligaciones laborales no solamente cuando se configuran los supuestos previstos en el artículo 1183 del Código Civil sino, además, en los casos en los que exista (...) fraude con el objeto de burlar los derechos laborales de los trabajadores". En efecto la solidaridad en las obligaciones laborales no puede enfocarse únicamente a partir de la norma contenida en el citado numeral, sino en función a otras variables, por ejemplo cuando se evidencie fraude con el objeto de evadir el cumplimiento de los derechos laborales de los trabajadores, siempre dentro del ámbito de protección de los beneficios sociales de los trabajadores cuyo carácter prioritario e irrenunciable ha sido consagrado en los artículos 24 y 26.2) de la Constitución del Estado.----

9.34 Así entendido y, existiendo indicios razonables que la empresa Cottonificio al efectuar la escisión empresarial con Tejidos Pisco, donde esta última se hacía cargo de los pasivos a partir de enero de 2008, empero, dejando sin patrimonio suficiente a la empresa escindida, lo que resulta un contrasentido, pues aquella no podría efectuar pago alguno de acreencias si es que no tiene bienes con que asegurar las mismas. De allí, que al existir indicios de fraude con el fin de evadir responsabilidades laborales, deviene en una evidente responsabilidad solidaria entre ambas empresas, pudiendo ser exigible la obligación demandada a cualquiera de ellas.

\section{PARTE RESOLUTIVA.}

POR ESTOS FUNDAMENTOS, ADMINISTRANDO JUSTICIA A NOMBRE DE LA NACIÓN, FALLO: DECLARANDO FUNDADA EN PARTE LA DEMANDA INTERPUESTA A FOJAS 339 A 355 SUBSANADA A FOJAS 360 A 362, POR EL SINDICATO DE TRABAJADORES DE LA FABRICA TEJIDOS PISCO SAC 
CONTRA LAS EMPRESAS COTTONIFICIO SUR PERU S.A.C. Y FABRICA DE

TEJIDOS PISCO S.A.C., SOBRE PAGO DE ACREENCIAS LABORALES;

ORDENO: QUE LAS CITADAS EMPRESAS PAGUEN EN FORMA

SOLIDARIA A FAVOR DEL ACTOR LA SUMA DE UN MILLON SETECIENCOS VEINTICINCO MIL OCHOCIENTOS CINCUENTIOCHO Y

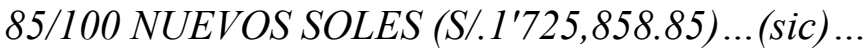

Como se puede observar, de este pronunciamiento se evidencian los serios problemas y grandes contingencias que se pueden generar por no tener los límites claros al momento de aplicar la Persecutoriedad y si bien coincidimos con el criterio del Juzgador en este caso, creemos que más allá del pronunciamiento debemos tomar nota del mensaje que nos deja el fallo y los fundamentos, precisamente porque por un lado se protege los créditos laborales pero por el otro no se ha puesto un freno a aquellos empresarios que intentan burlar la Ley un elemento disuasivo o que por lo menos implique desde ya una advertencia clara ante el cometimiento de este tipo de actos, en ambos lados hay perdidas, en ambas situaciones hay perjuicios, no se debe tolerar por un lado la Persecutoriedad automática e injustificada y dejarlo solo en las manos de los magistrados, sino que también hay que trasladar un poco el peso de esa responsabilidad al propio acreedor, no hay que caer en posiciones paternalistas que nunca han funcionado y en eso tenemos bastante experiencia. 


\section{CONCLUSIONES}

Estando a todo lo investigado y vertido en el presente trabajo podemos entonces extraer las siguientes conclusiones:

- La Ley nos brinda el siguiente concepto de escisión: por la escisión una sociedad fracciona su patrimonio en dos o más bloques para transferirlos íntegramente a otras sociedades o para conservar uno de ellos (Artículo 367). Debiendo mencionar que la mayoría de las doctrinas y las legislaciones que la incorporan a sus normas sustantivas efectúan una clasificación partiendo del elemento de la transmisión parcial o total de la sociedad que se escinde.

- Nuestra Ley General de Sociedades se establece a la letra en el artículo $389^{\circ}$ la responsabilidad de la sociedad escindida y aquella beneficiaria de la misma cuando nos dice: "Desde la fecha de entrada en vigencia de la escisión, las sociedades beneficiarias responden por las obligaciones que integran el pasivo del bloque patrimonial que se les ha traspasado a han absorbido por efectos de la escisión. Las sociedades escindidas que no se extinguen, solo responden frente a las sociedades beneficiarias por el saneamiento de los bienes que integran el activo del bloque patrimonial transferido, pero no por las obligaciones que integran el pasivo de dicho bloque". Texto que resulta sumamente claro y que es evidente ha optado siguiendo al profesor Beaumont: por uno de los caminos más modernos del derecho societario, en materia de escisión.

- La finalidad de la escisión empresarial no puede estar divorciada al principio que nos informa, por cuanto esta modalidad ha sido creada principalmente con una razón de ser y con un sentido real y sobre todo con una justificación que se advierta en los hechos y/o necesidades de la empresa devenida en demasiado grande y por ello inmanejable o por lo menos no económicamente rentable.

- Nuestra legislación ha definido los créditos laborales, entendido como las remuneraciones, la CTS, las indemnizaciones y en general los beneficios establecidos por la Ley que se adecuen a los trabajadores. Además, son créditos laborales los aportes impagos más intereses y gastos a los sistemas de jubilación 
conforme ha sido establecido a nivel legal por el Decreto Legislativo $\mathrm{N}^{\circ} 856$, protegido por nuestra Carta Magna, en su artículo $24^{\circ}$ segundo párrafo el principio del privilegio laboral y con carácter irrenunciable opera respecto de aquellos derechos expresamente reconocidos en la Constitución y la Ley

- Lo Ley nos informa el carácter persecutorio del crédito laboral, el cual constituye una respuesta clara del carácter protector del Derecho laboral, al privilegiar el crédito en tres supuestos:

a) Cuando el empleador ha sido declarado insolvente y como consecuencia de ello, ha procedido con la disolución y liquidación de la empresa o su declaración judicial de quiebra.

b) En los casos de extinción de las relaciones laborales e incumplimiento de las obligaciones con los trabajadores por simulación y/o fraude a la Ley, es decir, cuando se compruebe que el empleador injustificadamente disminuye o distorsiona la producción para originar el cierre del centro de trabajo o transfiere activos a terceros o los aporta para la constitución de nuevas empresas, o cuando abandona el centro del trabajo.

c) La preferencia o prioridad también se ejerce cuando en un proceso judicial el empleador no ponga a disposición del Juzgado bien o bienes libres suficientes para responder por los créditos laborales adeudados materia de la demanda.

- El criterio de que el derecho persecutorio no se limita a los supuestos descritos en el Decreto Legislativo $\mathrm{N}^{\circ} 856$ puede resultar a veces lesivo y en otras injustificadas teniendo como consecuencia un fundado temor en los inversionistas que atentaría en forma directa contra otro principio constitucional que es precisamente la seguridad jurídica en las inversiones.

- Nuestros tribunales han ido construyendo su tesis en lo que el legislador ha diseñado como mecanismo de protección de los créditos laborales que brota del propio artículo 24 de la Constitución. Por consiguiente, no estamos ante una mera garantía legal, sino ante una verdadera garantía constitucional conformante de la prioridad laboral señalada por el artículo 24 que devela el razonamiento que han venido realizando los Jueces a lo largo de los años que amplía en forma desmedida la posibilidad de activar el privilegio de la Persecutoriedad del crédito laboral. 
- Existe una reiterada tendencia a aplicar este privilegio sin más, omitiendo analizar si existió o no fraude. Lo que Indudablemente distorsiona la finalidad del "derecho persecutorio" y como corolario, resta seguridad al tráfico jurídico de bienes, a pesar de que aparentemente existen límites claros establecidos en la Ley General de Sociedades. Con considerables impactos en las empresas beneficiarias tanto en el primer momento por los elevados costos de transacción que significa mitigar los riesgos así como en un segundo momento verse afectado o disminuido en su patrimonio por la afectación de sus vienen por alguna acreencia laboral, lo que puede repercutir incluso dependiendo el tamaño de una empresa hasta en su quiebra.

- Es necesario poner límites claros a la aplicación del criterio de que toda deuda es perseguible y esto obviamente establecerlo casuísticamente (es decir analizar cada caso en concreto) porque de no presentarse supuestos en los que se pueda establecer un factor de atribución en las manifestaciones o rasgos sintomáticos característicos de una evasión laboral, o permitirnos constatar una situación de riesgo de incumplimiento laboral, no debería imputarse alguna responsabilidad solidaria entre la empresa beneficiaria y la empresa escindida. Asimismo, debe establecer claramente los límites de la responsabilidad de la empresa beneficiaria frente a una acreencia laboral de la empresa escindida, ya que, no puede ser una responsabilidad ilimitada.

- Creemos que ante una predectibilidad lirica de los fallos judiciales, es conveniente que se realicen mejoras o rediseños en la actual normativa por lo que resultaría necesario incluir en nuestra legislación una doble medida de protección que aun cuando sean diversas e, incluso, puedan operar sin influirse mutuamente, configuren una técnica principal (oposición) y otra complementaria (responsabilidad) que integren un mismo sistema unitario. 


\section{REFERENCIAS}

BEAUMONT CALLIRGOS, Ricardo. Comentarios a la Ley General de Sociedades. Lima: Editora Gaceta Jurídica.

BLANCAS BUSTAMANTE, Carlos. (1994). Los Derechos Laborales y la Estabilidad del Trabajo en la Constitución de 1993 En: La Constitución de 1993. Análisis y Comentarios, Comisión. Lima: Andina de Juristas.

CALliRgOS, R. M. (2006). Comentarios a la Ley General de Sociedades. Lima: Gaceta Jurídica.

CORTEZ CARCELEN, Juan. (2002). Los créditos laborales. Algunos temas de discusión. Lima: Análisis Laboral - Vol. XXVI N 301.

DUQUE DOMÍNGUEZ, J. (1987) La escisión de sociedades en el Anteproyecto de reforma parcial del Derecho de Sociedades. CDC, $\mathrm{N}^{\circ} 2$.

ECHAIZ MORENO, Daniel. Los grupos de empresas. Bases para una legislación integral. Lima, Fondo de Desarrollo Editorial de la Universidad de Lima, diciembre del 2001.

FERNÁNDEZ SESSAREGO, Carlos. (2001). Apuntes sobre el abuso de la personalidad jurídica. Lima: Advocatus, $\mathrm{N}^{\circ} 4$.

FERRO DELGADO, Víctor. (2009). El Principio de la Irrenunciabilidad en la Interpretación Jurisprudencial; en la obra colectiva Los principios del Derecho del Trabajo en el Derecho Peruano, Libro homenaje al profesor Américo Plá Rodríguez. Lima: Editorial Grijley.

GUASCH MARTORELL, Rafael. (1993). La escisión de sociedades en el derecho español: La tutela de los intereses de los socios y acreedores: Civitas S.A.

LOPEZ BASANTÍA, Justo. (1997). Instituciones de Derecho del Trabajo y de la Seguridad Social. México: AIADTSS-UNAM.

MONTOYA MANFREDI, U. (2004). Derecho Comercial. Lima: Grijley.

NEVES MUJICA, Javier. (1997). Introducción al Derecho del Trabajo. Lima: Ara Editores.

NEVES MUJICA, Javier. (2012). Introducción al Derecho del Trabajo. Lima: Fondo Editorial de la PUCP.

OTAEGUI, Julio C. (1981). Fusión y escisión de Sociedades Comerciales. Buenos Aires: Abaco de Rodolfo Depalma.

ROCA MENDOZA, Oreste. (2013). Ineficacia de los actos del deudor por fraude a los acreedores. Lima: Gaceta Jurídica. 
RUBIO CORREA, Marcial. (2001). Título Preliminar, Lima: Fondo Editorial de la Pontificia Universidad Católica del Perú

RUBIO CORREA, Marcial. (1999). Estudio de la Constitución Política de 1993. Lima: Fondo Editorial de la Pontificia Universidad Católica del Perú

SAMAMÉ MORANTE, Raúl, (2007). Los actos de desprendimiento patrimonial con posterioridad a la demanda de cobro de beneficios laborales, ¿son ineficaces?, Lima: Jus Jurisprudencia.

SILVA VALLEJO, José Antonio. (1985). El Artículo VII del Título Preliminar del Nuevo Código Civil: Llave Maestra de la Teoría General del Derecho Civil y Procesal, en Libro Homenaje a José León Barandiarán. Lima: Cultural Cuzco S.A.

TORRES VASQUEZ, Aníbal. La Jurisprudencia como fuente del Derecho fuente electrónica ubicada en la URL: http://www.etorresvasquez.com.pe/LaJurisprudencia.html.

TOYAMA MIYAGUSUKU, Jorge. (2005). La Constitución Comentada Artículo por Artículo. Lima: Gaceta Jurídica.

TOYAMA MIYAGUSUKU, Jorge. (2005). Derecho Persecutorio Laboral sobre el ex patrimonio del empleador. Lima: Gaceta Jurídica.

TOYAMA MIYAGUSUKU, Jorge. (2005). Derecho Persecutorio Laboral sobre el ex patrimonio del empleador. Lima: Dialogo con la Jurisprudencia - Gaceta Jurídica.

TOYAMA MIYAGUSUKU, Jorge. (2004). Instituciones del Derecho Laboral. Lima: Gaceta Jurídica.

URIA, Rodrigo. (1994). Derecho Mercantil. Madrid: Ediciones Jurídicas S.A. 